\title{
«Fleur du désert » : dom Éphrem Coutarel, un chartreux en révolution
}

"Fleur du Désert". Dom Éphrem Coutarel, a Carthusian in the Revolution

\section{Laurent Borne}

\section{(2) OpenEdition}

1 Journals

Édition électronique

URL : https://journals.openedition.org/ahrf/10736

DOI : $10.4000 /$ ahrf.10736

ISSN : 1952-403X

Éditeur :

Armand Colin, Société des études robespierristes

Édition imprimée

Date de publication : 1 janvier 2009

Pagination : 125-157

ISBN : 978-2-200-92557-4

ISSN : 0003-4436

Référence électronique

Laurent Borne, « «Fleur du désert » : dom Éphrem Coutarel, un chartreux en révolution », Annales historiques de la Révolution française [En ligne], 355 | janvier-mars 2009, mis en ligne le 01 janvier 2012, consulté le 23 avril 2022. URL : http://journals.openedition.org/ahrf/10736 ; DOI : https://doi.org/ 10.4000/ahrf.10736 


\title{
" FLEUR DU DÉSERT " DOM ÉPHREM COUTAREL, UN CHARTREUX EN RÉVOLUTION
}

Laurent BORNE

\begin{abstract}
Les premières mesures anticléricales ordonnées par l'Assemblée nationale à la fin de l'année 1789 sont perçues très tôt par les officiers majeurs de l'Ordre des chartreux comme autant d'entraves destinées à abolir un genre de vie monastique né de la réforme grégorienne. Parmi les chartreux français contestant le bien-fondé des réalités politiques et sociales qui se dessinent sous la plume ou le glaive des patriotes nationaux et locaux, se trouve un profès de Chartreuse : dom Éphrem Coutarel. Natif d'Auvergne et attiré dès l'enfance par l'existence solitaire et la spiritualité exigeante des fils de saint Bruno, sa vocation précoce pour l'Ordre et la rigueur de son noviciat en Chartreuse, le préparent à relever le défi de 1792. Opposant silencieux mais déterminé à l'occupation militaire et à la suppression de son établissement religieux, il réside seul durant deux ans dans le massif subalpin de Chartreuse et célèbre clandestinement le ministère paroissial. Incarcéré puis déporté en l'an II, il regagne les montagnes de l'Isère dès sa libération et griffonne toute une série de notes destinées à fossiliser le propositum cartusiense de la maison mère d'avant 1789. La confrontation des archives administratives gouvernementales et des souvenirs de ce chartreux contre-révolutionnaire permet de mieux cerner la personnalité et la trajectoire d'un moine à l'origine du retour des Pères de Chartreuse dans le massif en 1816.
\end{abstract}

Mots-clés : chartreux, christianisme, comité ecclésiastique, contrerévolution, écrits du for privé, Grande Chartreuse, histoire religieuse, Isère, itinérance, ministère clandestin.

«Fleur du désert ». Cette expression est employée au XIX ${ }^{\mathrm{e}}$ siècle par les chartreux dans leur «littérature grise» pour désigner les membres de l'Ordre qui s'exposèrent dangereusement ou qui payèrent de leur sang leur 
attachement à la religion durant la déchristianisation ${ }^{1}$. Comme le soulignait Bernard Delpal il y a près de quinze ans, les fils de saint Bruno « occupent une place singulière dans l'histoire de la Révolution $»^{2}$. Leurs rapports avec les nouvelles institutions, les hommes politiques et le peuple français sont «tendus », « déconcertants », souvent complexes voire équivoques. D’un côté, le prieur du Port-Sainte-Marie et sympathisant jacobin dom Gerle (26.10.1736-18.11.1801), député de Riom à la place du titulaire démissionnaire et auteur d'un mémorable discours à l'Assemblée constituante, le 12 décembre 1789. De l'autre, plus de cinquante religieux (5\% de l'effectif total des chartreux de 1790) ${ }^{3}$ qui meurent en prison ou sur l'échafaud pour s'être opposés à l'ordre nouveau en défendant activement, par le prêche et le goupillon, les « hochets de la superstition ». Il existait dans les chartreuses de France une résistance venant de toutes les familles de pensée, de toutes les classes d'âge et de tous les milieux sociaux. De la bourgeoisie, de l'aristocratie, du commerce et du monde paysan, une foule d' « habitants du désert » refusait d'être « témoin ou participant de la régénération de cet empire » si ardemment souhaité par dom Gerle, un soir de décembre ${ }^{4}$. Parmi ces religieux figure « en première ligne $»^{5}$ un père de Chartreuse natif d'Auvergne : dom Éphrem Coutarel (27.03.1764-09.03.1842). Sa trajectoire est notamment connue par les témoignages et les Usages de Chartreuse qu'il dicta à l'automne de sa vie à dom Jean Sallier (1806-1861) ${ }^{6}$, père Maître de Chartreuse, entre 1836 et 1838. Considéré par ses contemporains et successeurs spirituels comme un « ange consolateur », ce moine devenu aveugle allait jouer un rôle primordial dans le rétablissement de l'Ordre au début des années 1810-1830, guidé par des convictions forgées lors des combats menés durant la Révolution.

\section{Aux sources de l'engagement contre-révolutionnaire (1764-1789)}

Jean Coutarel voit le jour le 27 mars 1764 à Freyssinoux ${ }^{7}$, petit village rural niché aux confins des hautes terres froides du Gévaudan et

(1) Archivum Majoris Cartusice [Archives de la Grande Chartreuse, on notera désormais simplement AMC], n.c., notices biographiques, $\mathrm{XIX}^{\mathrm{e}}$ siècle.

(2) Bernard Delpal, « Les chartreux et le Comité ecclésiastique (1789-1790) », Crises et temps de rupture en Chartreuse, $X I V^{\mathrm{e}}-X X^{\mathrm{e}}$ siècles, Analecta Cartusiana [AC], nouvelle série, VI, $\mathrm{n}^{\text {os }} 11-12,1994$, p. 147-164.

(3) AMC, R $127^{\mathrm{D}}$, Les chartreux martyrs de la foi durant la Révolution française, $84 \mathrm{p}$.

(4) M.J. Mavidal, Archives parlementaires de 1787 à 1860, $1^{\text {re }}$ série, X, Paris, 1878, p. 526-27.

(5) L'expression est d'un chartreux. AMC, 7 Géné 4 (C).

(6) Dom Victor-Marie Doreau, Vie du père dom Jean Sallier de l'Ordre des chartreux, Paris, $1888,381 \mathrm{p}$.

(7) Archives départementales $[A D]$ du Cantal, 2 E 107.1, registre de catholicité de la paroisse de Lorcières, $n . f^{\circ}, 28$ mars 1764 . Il est porté sur les fonds baptismaux le lendemain. 
de l'Auvergne, dans la paroisse de Saint-Sébastien-Lorcières (Cantal). Aîné d'une fratrie de neuf enfants, il réside durant son enfance auprès de ses parents, Guillaume Coutarel (26.08.1742- $\uparrow$ ?) et Catherine Lèbre (08.05.1743-03.03.1804), dans un milieu caractérisé par un certain confort matériel. Les Coutarel, et davantage les Lèbre, comptent parmi les familles les plus importantes de la paroisse, tant par le statut social de certaines branches que par le nombre des porteurs des deux patronymes.

Forte de douze foyers, la famille Coutarel habite les hameaux de Feyrolette, de Marcilhac, de Freyssinoux et le bourg de Lorcières depuis le milieu du XVI $\mathrm{XIècle}^{\mathrm{e}}$. Le fondateur de la lignée est inconnu mais très tôt les Coutarel occupent des fonctions importantes dans cette paroisse et prévôté ecclésiastique de cent-cinquante-sept feux ${ }^{8}$. Un Guillaume Coutarel sert la cure de Lorcières entre 1569 et 1607, un autre est qualifié de «messire » dans les registres de catholicité de la fin du XVI et du début $\mathrm{du} \mathrm{XVII}^{\mathrm{e}}$ siècles $^{9}$. Le père de Jean et ses oncles deviennent consuls et gèrent la fabrique entre 1763 et 1768. Enfin, plusieurs laboureurs exploitent des domaines qui ne cessent d'être arrondis de génération en génération, au détriment des autres paroissiens. La dynastie Lèbre, dont la présence dans la paroisse et dans le village de Chaleilles est attestée dès 1570, est aussi réputée pour sa belle fortune. Le lignage connaît une ascension sociale remarquable à l'orée du XVIII ${ }^{e}$ siècle. Le bisaïeul et le grand-père de Jean, surtout, disposent d'une assise financière appréciable qui autorise des investissements fonciers réguliers à la limite des paroisses de Clavières et de Lorcières entre 1746 et $1760^{10}$.

Les noces des parents de Jean, le 27 janvier 1763, scellent l'union entre les deux maisons de Freyssinoux et la fusion des patrimoines. Le rôle du troisième vingtième, dont la levée est motivée par la guerre de Sept ans (1756-1763) puis prorogée, permet de mesurer l'étendue de leurs ressources et d'estimer les revenus de leurs propriétés : Guillaume Coutarel, « laboureur par succession » de Jean Lèbre (28.02.1704-16.07.1778), son beau-père, est présenté par les contrôleurs du vingtième comme l'un « des plus riches de la paroisse ». Ce petit « coq de village » détient un

(8) Claude Marin SAUgrin, « Lorcières », Nouveau dénombrement du royaume par généralités, élections, paroisses et feux, $1^{\text {re }}$ partie, Paris, 1735, p. 159 ; M. DÉRIBIER DU CHÂTELET, Dictionnaire statistique, ou histoire, description et statistique du département du Cantal, t. IV, Aurillac, 1856, p. 29-36.

(9) AD Cantal, 2 E 107.1, n.fo, 15 mai 1569-29 avril 1570, 15 janvier 1603-27 mai 1603, 15 juillet 1605-30 mai 1606, 23 juillet 1606-29 mars 1607 .

(10) Ils dépensent, et c'est un minimum, plus de 2685 lt. pour des terres et des prés. AD Cantal, C 259, Ventes faites par Marie-Madelaine Simon Lombard de la paroisse de Clavières à Jean Lebre laboureur du lieu et paroisse de Fraissinoux, paroisse de Lorcières, 1777. 
moulin, quatre paires d'attelage de bœufs et plusieurs héritages à Lorcières et Freyssinoux. En 1763, il paie à lui seul $8 \%$ du vingtième de la paroisse $^{11}$. Les rôles de taille et de capitation de 1763 à 1768 confirment cette relative aisance. Guillaume figure, avec son beau-père, parmi les contribuables les plus taxés, juste derrière les «bourgeois » Simon et Barthélemy Coutarel, qui jouissent de « domaines considérables » qu'ils font valoir par des domestiques ${ }^{12}$.

Jean s'épanouit et reçoit une éducation soignée dans une famille prospère en compagnie de ses quatre frères et quatre sœurs. L'inventaire après-décès des Coutarel n'a pas été découvert, et nous ne pouvons guère apprécier la place que le livre, et notamment le livre religieux, occupait dans ce foyer, encore moins dans la vie de l'enfant. Il est en revanche avéré que la famille était lettrée, proche de la religion et des préceptes de l'Église sur le mariage et la fécondité. Guillaume Coutarel communie presque tous les jours. Avec neuf enfants atteignant tous l'âge adulte, son foyer est caractérisé par un taux de natalité important, supérieur aux moyennes généralement observées dans les familles pourvoyeuses de vocations monastiques (de 6,6 à 6,9 enfants $)^{13}$. Contrairement à son père et à la majorité des fidèles de Lorcières, il sait aussi écrire. Il émarge durant treize ans (1771-1783) les registres paroissiaux de Saint-Sébastien-Lorcières, lors de la naissance de ses enfants ou à l'occasion des relations de sociabilité qu'il entretient avec les villageois des douze localités de la paroisse, quand il assiste à leurs mariages ${ }^{14}$. À en croire dom Jean Sallier, le petit Coutarel, « doué des plus heureuses dispositions pour la vertu », suit l'exemple de ses «pieux parents » et notamment de son père, à qui il porte une affection peu ordinaire. Jean prend « un singulier plaisir à [1']entendre parler de la vie religieuse $\rangle^{15}$. Il s'instruit aussi en compagnie de son oncle, Antoine Lèbre (1737- $\dagger$ ?), prêtre-filleul de Lorcières, chanoine de l'ordre de Saint-Augustin et vicaire des paroisses

(11) AD Cantal, C 259, minutes du rôle du vingtième de la paroisse de Lorcières, art. 9, 10, 40-42, 58 et 76-77. En 1763, le total du troisième vingtième s'élève à 843 lt. $15 \mathrm{~s}$. et $9 \mathrm{~d}$.

(12) AD Cantal, C 577, rôles de taille et de capitation de Lorcières (1732-1769).

(13) Guy Brunet et Alain BideAu, «La vocation sacerdotale : une affaire de famille », Annales de démographie historique, 2004, $\mathrm{n}^{\circ} 1$, p. 222 ; Philippe ARIĖs, Histoire des populations françaises et de leurs attitudes devant la vie depuis le XVIII ${ }^{e}$ siècle, Paris, 1971, p. 318 ; Jean-Pierre BARDET, «La chute de la fécondité : les incertitudes de l'explication », Histoire de la population française, vol. 3, Paris, PUF, 1988, p. 376.

(14) AD Cantal, 2 E 107/2, registre de catholicité et d'état-civil de Lorcières (1771-1792), n. $f^{\circ}$

(15) AMC, n.c., Notice biographique sur dom Éphrem Coutarel, profès de Chartreuse, décédé en Chartreuse, le 9 mars 1842, $\mathrm{f}^{\circ} 1 \mathrm{r}$. 
voisines de Clavières (1768) et de Saint-Just-de-Recoux (1781). Ce dernier lui inculque sans doute ses premières notions de catéchisme, de latin, et l'initie aux humanités. L'influence des ecclésiastiques Lèbre sur les pratiques cultuelles et spirituelles de la famille Coutarel est grande : si le grand-père Jean parraine le petit Coutarel, aîné masculin et premier enfant de la fratrie, sa fille, Agnès Lèbre, dominicaine, présente la première fille des Coutarel-Lèbre sur les fonds baptismaux (26.01.1766), et le prêtre Antoine, le troisième enfant, une fille (07.06.1768), et le deuxième descendant mâle (08.09.1773) du couple.

En endossant le rôle de précepteur mais aussi de directeur de conscience, l'oncle assiste voire remplace les prêtres-communalistes Ollier (1737-1779), Chassang, Valentin et Crozatier (1780-1789) ${ }^{16}$ dans l'éducation chrétienne du petit. L'existence d'un oncle prêtre peut favoriser et diriger une vocation sur le chemin d'une carrière sacerdotale. Prenant appui sur les enquêtes réalisées par Philippe Boutry sur le Valromey ${ }^{17}$, Guy Brunet et Alain Bideau considèrent que la présence d'un oncle prêtre est un "élément déterminant, créant des "dynasties" de prêtres ». Ils signalent ainsi les cas remarquables d'une vingtaine de prêtres issus des familles Genolin et Humbert de Champfromier, dans la vallée de la Valserine, à la frontière de l'Ain et du Jura ${ }^{18}$. Des résultats analogues sont obtenus dans le diocèse plus proche de Clermont par Stéphane Gomis et Cyrille Fayolle ${ }^{19}$. L'ascendant de l'oncle sur le jeune Jean Coutarel paraît décisif, mais n'est pas aussi fort que l'attrait du monastère ${ }^{20}$. Les exemples familiaux n'invitent pas le petit Coutarel à embrasser le sacerdoce clérical, encore moins à rentrer chez les disciples de saint Dominique, où l'une de ses tantes maternelles avait pris le voile ${ }^{21}$.

(16) AD Cantal, 346 F 42, prises de possession de la cure de Lorcières (XVIII ${ }^{\mathrm{e}}$ siècle).

(17) Philippe Boutry, Prêtres et paroisses au pays du curé d'Ars, Paris, Le Cerf, 1986, p. 196 et $s q q$.

(18) Guy Brunet et Alain Bideau, art. cit. p. 215-228.

(19) Stéphane Gomis, Les « Enfants prêtres » des paroisses d'Auvergne, XVI ${ }^{e}$-XVIII ${ }^{e}$ siècles, Clermont-Ferrand, Presses Universitaires Blaise Pascal, 2006, p. 337 et sqq.; Cyrille Fayolle, "L'entrée en religion. Déterminations sociales et décision personnelle », Vocations d'Ancien Régime. Les gens d'Église en Auvergne aux XVII' et XVIII' siècles, Revue d'Auvergne, 1997, 544-545, p. 119.

(20) Dominique Dinet fait la même constatation. Dominique DinET, Vocation et fidélité. Le recrutement des Réguliers dans les diocèses d'Auxerre, Langres et Dijon (XVII'-XVIII'), Paris, 1988, p. 41.

(21) Elle prononce ses vœux solennels dans le couvent des dominicaines de Saint-Joseph de Murat, AD Cantal, 2 E 107.1, n.f ${ }^{\circ}, 26$ janvier 1766. 

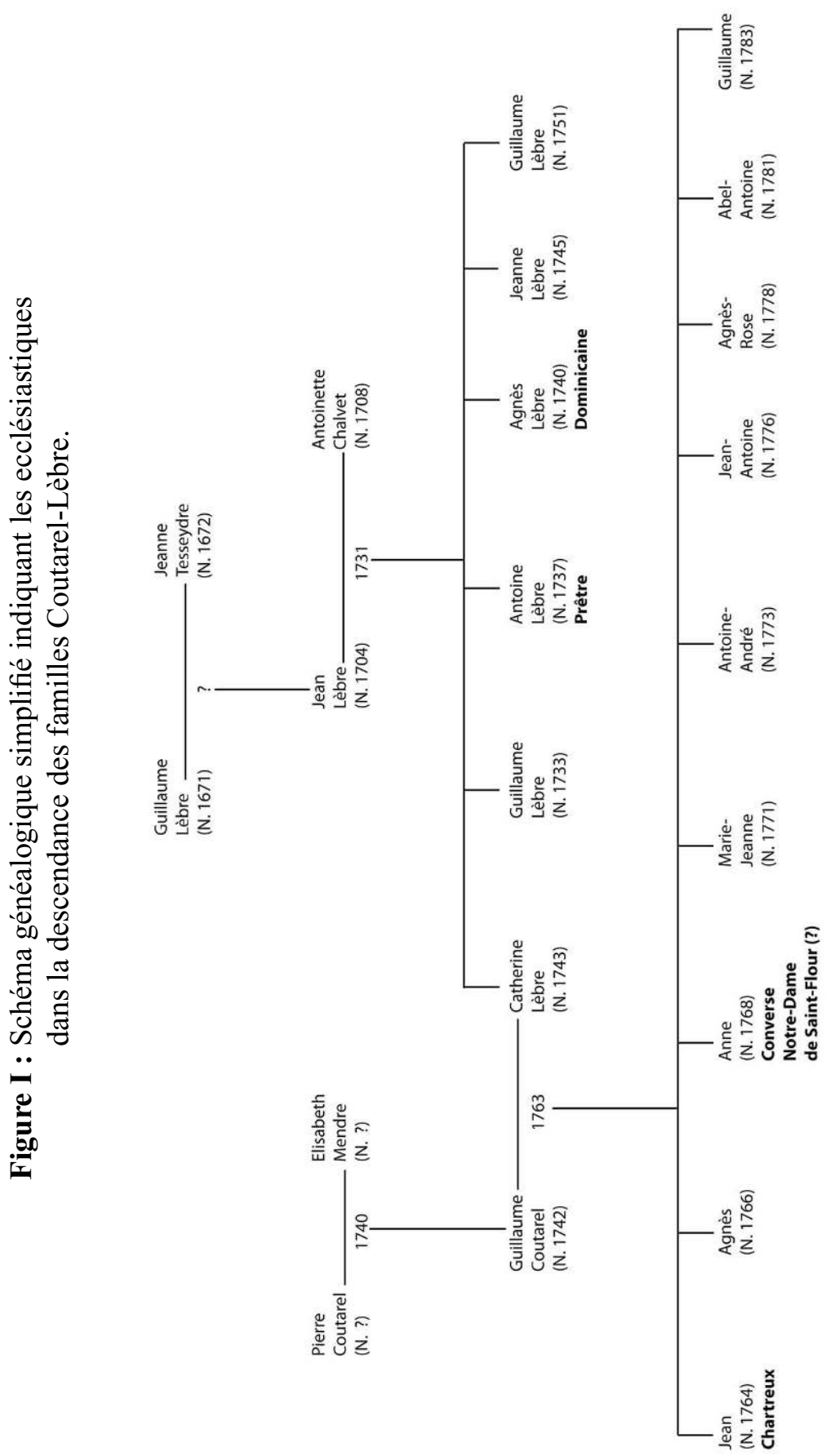
Pour Dominique Dinet, l'engagement délibéré et la manière de vivre sa foi dans un institut particulier, avec un genre de vie spécifique, ne sont pas des actes gratuits : pauvreté des franciscains, prédication des dominicains, austérité de la Trappe, intérêt pour l'enseignement chez les prémontrés et les mauristes... autant de raisons susceptibles d'entraîner des adhésions ${ }^{22}$. Chez Jean, l'invitation à la religion doit être recherchée loin d'un isolat géographique distant d'une à quatre heures de chevauchée du gros bourg de Ruynes-en-Margeride et de la cité épiscopale de SaintFlour, où, semble-t-il, il n'effectue pas le reste de ses études et où il ne désire pas rejoindre le couvent des jacobins ${ }^{23}$. Son inclinaison le porte davantage vers l'Ordre des chartreux. Il le découvre à l'occasion des récits pittoresques rapportés par un domestique de la chartreuse provençale de Valbonne (Gard $)^{24}$ qui passait quelquefois à Lorcières, dans la décennie 1774-1784. Avide du moindre détail, les informations qu'il glane sur la vie d'une communauté cartusienne (1204-1792) en pleine prospérité spirituelle et temporelle à la veille de la Révolution, suscitent en lui une vive émotion. Elles alimentent son imagination, bien plus encore que les légendes et mises en garde qui circulent toujours sur le "monstre» anthropophage qui sévissait quelques années plus tôt dans la paroisse et qui jetait encore « la consternation dans l'esprit des peuples $»^{25}$. De l'aveu du futur moine, ces entretiens rompent la monotonie de son adolescence. Le jeune homme sent «naître en lui un secret désir, que chaque jour il [voit] croître » : celui de devenir chartreux ${ }^{26}$. Informé lors d'une confession, son oncle, un « homme prudent », l'éprouve durant plusieurs mois avant de lui délivrer une autorisation pour « aller faire l'essai de ce genre de vie après lequel il soupirait si ardemment $\rangle^{27}$. Jean Coutarel, qui ne s'était jamais rendu à Valbonne mais qui prévoyait toujours d'y prononcer ses vœux, prend la route de Langeac à l'âge de 20 ans puis chevauche vers

(22) Dominique Dinet, op. cit., p. 32-47.

(23) Nulle trace de lui dans les papiers du séminaire ni dans l'ouvrage de Pierre Chassang, Le Grand séminaire de Saint-Flour : Trois siècles d'une riche et féconde histoire (1651-1959), SaintFlour, 1994, $177 \mathrm{p}$.

(24) Paul Amargier, Régis Bertrand, Alain Girard, Daniel Le Blévec, Chartreuses de Provence, Aix-en-Provence, 1988, p. 28-30.

(25) AD Puy-de-Dôme, 1 C 1738. D'après la relation qu'en donne le curé Ollier de Lorcières à l'intendant d'Auvergne, la « bête du Gevaudan » tue et blesse grièvement plusieurs villageois et villageoises de La Besseyre-Sainte-Marie, Chauliac, Marcilhac, Clavières et La Fage durant le mois de décembre 1765 .

(26) AMC, n.c., Souvenirs du vénérable père dom Étienne (sic) Coutarel, mort à la Grande Chartreuse en $1842, \mathrm{f}^{\circ} 2 \mathrm{v}$.

(27) Ibid., $\mathrm{f}^{\mathrm{0}} 2 \mathrm{v}$. 
la chartreuse la plus proche de son village : celle du Puy-en-Velay (HauteLoire). Dom Jean Sallier indique qu'il y est reçu vers 1784 par dom Guillaume Puel, qui gouverne la communauté depuis trois ans. Cet officier de 51 ans, rompu aux charges, lui conseille la chartreuse du PortSainte-Marie (Puy-de-Dôme) où les novices faisaient défaut, et lui demande d'attendre chez lui la réponse du prieur de cette maison de Basse-Auvergne (1219-1792) qu'il se propose de contacter pour obtenir son admission. L'attente fut tout au plus de quelques mois.

Désireux d'évoquer l'« énergie de caractère » de Jean et le réconfort que lui procure le « secours divin », dom Sallier présente son départ de la manière suivante : « comme un nouveau Louis de Gonzague (15681591), ou un autre François d'Assise (1182-1226), il réussit à rompre généreusement les liens de la chair et du sang, en faisant à Dieu le sacrifice de ses affections et de sa liberté ; il quitte gaiement cette maison paternelle [...], où son absence allait faire couler tant de larmes, et clouer même pendant plusieurs mois son père bien-aimé sur un lit de douleurs $»^{28}$. Le biographe utilise une image forte et l'analogie avec Louis de Gonzague, qui renonce solennellement à la succession de son père au profit de son frère Rodolphe le 2 novembre 1585, n'est sans doute pas innocente. Il s'agit d'une anecdote, celle d'une rupture familiale douloureuse que l'on retrouve dans d'autres récits de chartreux, aux XVII et XVIII siècles, et qui bien sûr confine au topos. Mais il n'est pas inutile de rappeler ici cette séparation. Elle permettra de mieux comprendre l'engagement du chartreux lorsque le 13 février 1790 sonnera l'heure du choix entre la vie civile, que l'Assemblée nationale offre aux religieux en prononçant la suppression des communautés à vœux perpétuels, et le maintien de l'existence commune en maison de réunion selon des modalités à régler dans chaque cas.

Finalement, Jean se rend au Port-Sainte-Marie en 1784. À cette époque, le candidat doit faire un postulat d'un mois, durant lequel il s'initie aux rudiments de la liturgie, du chant et des usages de la maison. Si le maître des novices, à la fin de cette période, estimait qu'on pouvait le recevoir au noviciat, il le présentait au groupe, qui votait. Au bout d'un mois, Jean reçoit les suffrages des profès de la chartreuse, prend l'habit de novice et suit alors tous les exercices du groupe religieux. Dans les premiers temps de son noviciat, le jeune Coutarel fait preuve d'un rigorisme inquiétant et considère qu'on ne l' «humili[e] et ne [l']éprouv[e] pas

(28) AMC, n.c., Notice biographique..., f 5 r. 
assez $»^{29}$. Il s'oppose notamment au père Maître chargé de son encadrement, critique la gestion du temporel et les travaux de restauration du couvent qu'entreprend le prieur dom François Bertrand, qu'il juge trop somptueux et contraires à l'esprit de simplicité des premiers pères chartreux. De crainte de ne pouvoir être admis à faire sa profession solennelle, si après un an de noviciat le vote de la communauté le permettait, Jean suit les conseils de son père Maître qui l'engageait à se rendre à la Grande Chartreuse, où le propositum cartusiense était plus draconien et où les candidats pointilleux étaient souvent redirigés à l'époque moderne. Il y entame sa probation, en cellule « $\mathrm{R}$ », le 4 décembre 1785, début des fêtes calendales et jour de la Sainte-Barbe, dont le culte est souvent associé à la germination des céréales et des légumineuses en Dauphiné. Si les semences ont germé au 25 décembre, la récolte sera florissante; or à ses débuts la «pousse Coutarel » présente des signes de faiblesse alarmants et le noviciat s'apparente davantage à un temps de contrariétés et de doutes qu'à une corne d'abondance. Le candidat est très mal reçu par le prieur dom Hilarion Robinet (1778-1791) et par le nouveau père Maître dom Thadée Forestier (1785), qui souhaitent son renvoi. Il essuie également les quolibets des autres novices et fait l'objet de « rapports » que les frères et domestiques de la maison s'empressent de communiquer aux officiers majeurs. Seul le vicaire de Chartreuse, son voisin de cellule, le soutient. Il convainc le reste des pères de l'admettre au noviciat, ce qu'il obtient le 13 janvier 1786, jour où Jean meurt au monde, en revêtant la livrée blanche des fils de saint Bruno et en choisissant le prénom d'Éphrem ${ }^{30}$.

Dom Éphrem poursuit son noviciat sans embarras et prononce ses vœux solennels en présence du révérend père Hilarion Robinet le 14 janvier 1787. Le 7 octobre de la même année, il reçoit à la Grande Chartreuse des mains du récent prince-évêque de Genève Joseph-Marie Paget (03.01.1787-04.02.1802), la première tonsure, les quatre ordres mineurs et le sous-diaconat en compagnie de sept puis neuf acolytes ${ }^{31}$. Il est nommé diacre le lendemain. Jean-Denis Devienne, évêque titulaire de Sarepta, vicaire général de Lyon et chanoine de l'église Saint-Paul le fait prêtre en Chartreuse trois jours avant la prise de La Bastille ${ }^{32}$. Les pièces

(29) AMC, n.c., Souvenirs..., f 2 r.

(30) AMC, n.c., Souvenirs de dom Éphrem Coutarel; usages de la Grande Chartreuse avant la Révolution, n.f ${ }^{\circ}$.

(31) AMC, 5 Hist. 45, Collectio ordinationum professorum Cartusice ab anno 1676 usque ad annum 1779 inclusive, n. $\mathrm{f}^{\circ}$.

(32) Ibid. 
Figure II : Portrait de dom Éphrem Coutarel, chartreux, s.d. (XVIII' s.).

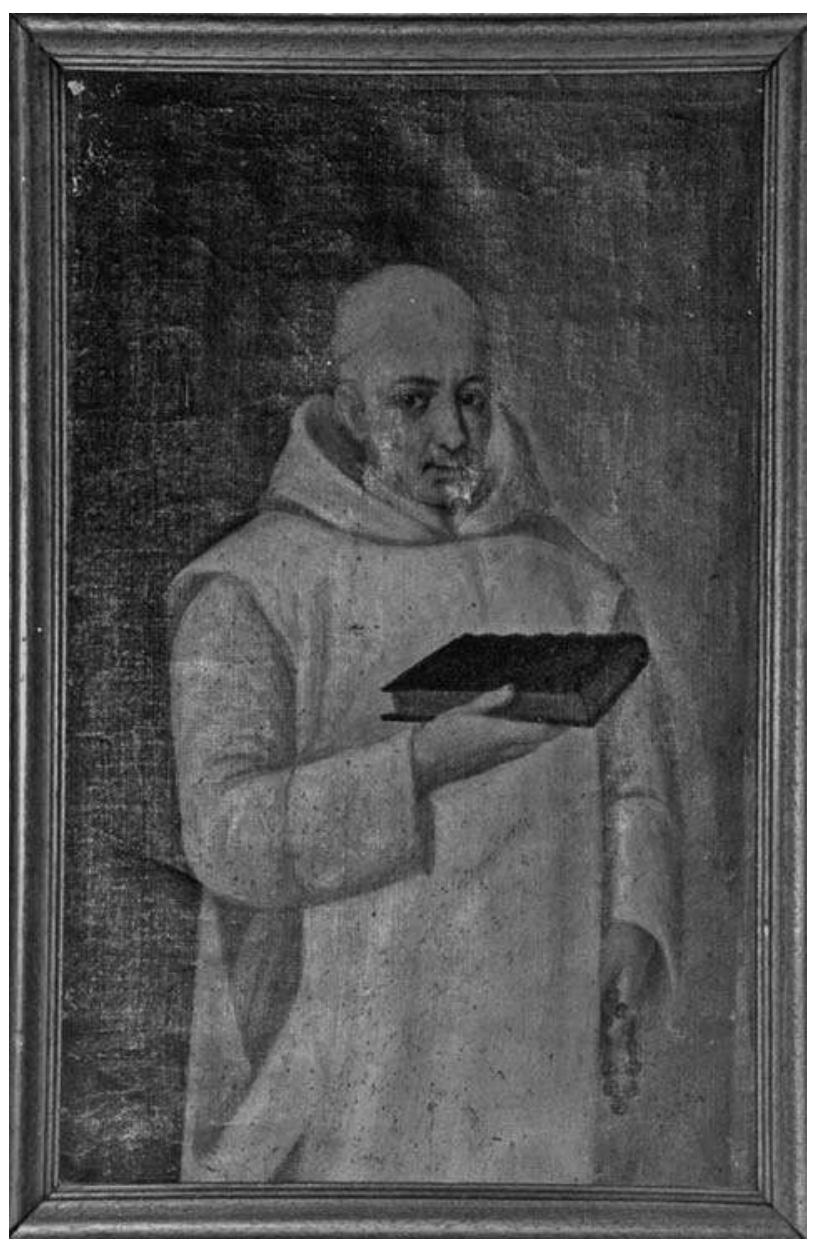

Coll. particulière C URAC, 2007.

d'un savant puzzle pouvaient désormais s'emboîter à la faveur de la précipitation des événements politiques nationaux et régionaux. Vocation précoce pour les chartreux, rupture avec un milieu familial dévot et protecteur, rigorisme, noviciat semé d'embuches mais fortifiant : autant de motifs qui allaient inciter dom Éphrem à emprunter les chemins de la résistance face aux premières mesures anticléricales édictées par l'Assemblée nationale constituante et la suppression par la Législative des corporations religieuses, conséquence logique de la loi Le Chapelier, le 18 août 1792. 


\section{Résistance commune (1790-1792)}

Dans le cloître, dom Éphrem et les pères de Chartreuse sont informés des nouvelles de la France et du monde par le révérend père, qui les sélectionne dans les journaux de tendance royaliste et modérée qu'il reçoit de Grenoble ${ }^{33}$. Au tout début de la Révolution, les renseignements qu'il filtre dans la presse et dans les relations écrites que donnent de leurs situations les autres chartreuses françaises semblent plutôt bons; à l'image des rapports entre les fils de saint Bruno et l'État. En apparence, les bruits du siècle n'affectent presque pas l'existence d'une communauté monastique numériquement importante, assez jeune et relativement épargnée par les difficultés de recrutement, à en juger par le matricule tenu depuis 1785 par dom Thadée Forestier et les déclarations des religieux aux agents municipaux de Saint-Pierre-de-Chartreuse en $1790^{34}$.

Figure III : Les professions des moines de chœur en Chartreuse à la veille de la Révolution (1717-1789)

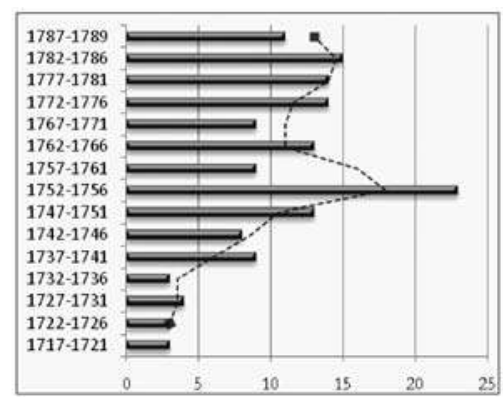

Figure IV : Âge des moines de chœur en Chartreuse en 1790

(33) AMC, 5 Hist. 11. Le Patriote françois de Brissot, L'ami du Roi de l'ultraroyaliste Thomas Marie Royou, les Annales monarchiques, philosophiques, politiques et littéraires, de tendance royaliste, enfin, Le Courrier d'Avignon (1789-1790) puis Journal politique d'Avignon (1790). Ils ne semblent pas recevoir Les affiches du Dauphiné, feuille monarchiste, ni le Journal patriotique de Grenoble. Les AMC conservent encore quelques épaves de ces journaux. Après l'exil, les Pères lisent des journaux de tendance royaliste et antirévolutionnaires, tels le Journal de Perlet (1795) et Le Gardien de la Constitution (1796).

(34) AMC, 5 Hist. 28, Catalogue des Profés (sic) vivans de Chartreuse de Dom De Montgeffond, 1785 ; AMC, 5 Hist. 22, Inventaires de la Chartreuse, 1790-1792, p. 20-24. Avec une moyenne d'âge de 41,6 ans, la communauté de Chartreuse est plus vieillissante que celle de Champmol, moins nombreuse (32,1 ans, 21 moines de chœur). En 1789-90 plus de la moitié des pères de Chartreuse ont moins de 40 ans. Le monastère est l'un des seuls établissements réguliers de l'Isère, avec les capucins de Vienne, de Grenoble, de Crémieu et de La Mure, à disposer d'un noviciat florissant. Dominique DINET, op. cit., p. 256-257 ; A.-M. DE FRANCLIEU, La persécution religieuse dans le département de l'Isère de 1790 à 1802, I, Tournai, 1904, p. 296. 
Dans ses mémoires, dom Éphrem ne fait pas cas des événements de 1789 , et notamment du passage, en octobre, de révolutionnaires venus recueillir les actes de baptême et de profession des religieux ${ }^{35}$. La position favorable des chartreux à l'époque permet d'expliquer ce silence. À l'automne, les pères jouissent d'un certain crédit auprès des patriotes et des principaux membres du Comité ecclésiastique. Les 39 moines et 50 frères de Chartreuse $^{36}$, Chalais et Currière compris, et plus communément l'Ordre, ne sont guère soupçonnés par l'Assemblée de pervertir les idéaux et traditions de leur fondateur ni d'héberger, comme les autres familles de réguliers, « d'orgueilleux possessionnés [...] livrés à la paresse et à l'oisiveté $»^{37}$. D'un autre côté, les premières mesures prises par l'Assemblée éveillent la méfiance des chartreux. La connaissance par la presse des décrets de l'Assemblée nationale, et notamment du discours de Treilhard du 17 décembre 1789, et la mise en application de l'arrêt du 13 février 1790 sur la nationalisation des biens du clergé et l'interdiction des vœux « de l'un et l'autre sexe », provoquent davantage d'inquiétudes dans les cloîtres. La rhétorique de Treilhard, qui quelques jours après le vote de son décret avait conseillé aux députés de chercher dans la vente des maisons de Cluny, " de saint Bruno, [de] saint Bernard et [de] saint Vanne » les seize millions supplémentaires nécessaires aux traitements des religieux pensionnés, alarme le général des chartreux et les officiers majeurs de la province cartusienne de Provence qui tentent de retarder l'application de la $1 \mathrm{loi}^{38}$.

Fin février, la disparition des réguliers devient prévisible pour bon nombre de chartreux. Elle l'est aussi pour les officiers municipaux et quelques nobles ou calotins influents de Grenoble qui confient à l'Assemblée nationale, dès janvier, un mémoire demandant la conservation des monastères de Chartreuse, de la visitation, des ursulines, des hospitaliers et des hospitalières du district, dont les activités charitables sont jugées nécessaires au public ${ }^{39}$. Ils ne sont pas les seuls à l'entrevoir. Impatients

(35) AD Isère, 1 Q 360, extrait des actes baptistaires et de profession des religieux (29 octobre 1789). À cette date, il y avait 32 pères (1 sort de l'Ordre le 22 mai 1790), 16 convers et 32 donnés (6 quittent le monastère en 1790-1791).

(36) Dom Augustin Devaux, «La croissance numérique des chartreux français à la fin du XVIII ${ }^{e}$ siècle. Une nouvelle légende ", Crises et temps de rupture en Chartreuse, $X I V^{e}-X X^{e}$ siècles, Analecta Cartusiana, nouvelle série, VI, nos 11-12, 1994, p. 135-145.

(37) Bernard DelPal, art. cit., p. 147-164.

(38) Treilhard, Le Moniteur, III, séance du 17 février 1790, p. 399 ; cité par Bernard DelPAL, art. cit., p. 151.

(39) A.M. Grenoble, BB 128, Mémoire des officiers municipaux de la ville de Grenoble à M.M. les députés de la province à l'Assemblée nationale (janvier 1790). 
d'acquérir les terres cartusiennes, les paysans du massif et plusieurs bandes armées des environs avaient anticipé la dislocation de la communauté de Chartreuse et la nationalisation du plus gros patrimoine ecclésiastique de l'Isère ( $73 \%$ du total des biens du clergé du département $)^{40}$ en réclamant les terriers durant l'été $89^{41}$. Pour bien d'autres raisons et bien avant l'application du décret Treilhard, ils espéraient beaucoup de la mise en vente d'un vaste domaine contigu $\left( \pm 25 \mathrm{~km}^{2}\right)$, s'étendant sur les communes de La Ruchère, Miribel-les-Échelles, Saint-Laurent-du-Pont, Entre-Deux-Guiers, Saint-Christophe, Voreppe, Pommiers, Saint-Étiennede-Crosey, La Buisse, Saint-Jullien-de-Ratz, Quais, Sarcenas, SaintMartin-le-Vinoux et Le Sappey. Dom Éphrem, a contrario, redoute cette éventualité. Elle se concrétise entre le 31 décembre 1790 et le 30 mai 1791. Durant cette période, le temporel cartusien autre que les forêts, prairies, usines et bâtiments monastiques réservés par l'État, commence à être vendu à des bourgeois et à des négociants de Voiron et de Grenoble, échappant ainsi aux appétits des cultivateurs ${ }^{42}$.

Pour la première fois depuis le début de la Révolution, les événements de 1790 sont l'occasion pour notre chartreux de se confronter par lui-même aux idées nouvelles. Dès les premiers mois de 1790, les pères et frères de Chartreuse demeurent passifs face à la politique du Comité ecclésiastique. Ils ressentent difficilement les événements du printemps. Le décret complémentaire du 20 mars, enjoignant aux municipalités de visiter les couvents et de recueillir les déclarations de leurs occupants, est mal accueilli par les chartreux et les perturbe autant que la saisie et la vente du mobilier liturgique et des terres. Dom Coutarel ne pense ni ne souhaite abandonner le couvent et s'oppose à toute remise en cause du spirituel et de la règle en vivant selon le Statut. Il suit en cela l'exemple du révérend père, qui montre la marche à suivre. Pour s'en convaincre, il suffit d'examiner les rapports rédigés au monastère par les agents municipaux de Saint-Pierre-de-Chartreuse avant la fête de la Fédération. Les actes de désobéissance sont nombreux. Retenons ici trois faits marquants : tout d'abord, l'élection sans véritable protocole de nouveaux officiers, le 2 mai, selon « la forme ordinaire des délibérations capitulaires » et au

(40) D'après l'estimation de Pierre Arsac, La vente des biens de la Grande Chartreuse sous la Révolution, Université des Sciences Sociales de Grenoble, Grenoble, 1984, p. 10.

(41) Jean GodEL, « La Révolution française et le clergé dauphinois, 1788-1791 », dans Vital Сномец, Les débuts de la Révolution française en Dauphiné, Presses Universitaires de Grenoble, Grenoble, 1988, p. 219.

(42) Un seul cultivateur a pu acquérir une propriété provenant de la vente des biens cartusiens. Pierre ARSAC, op. cit., p. 43-56. 
mépris du droit révolutionnaire ${ }^{43}$; ensuite, la garde et la gestion du « désert » de Chartreuse revendiquées le 5 mai par la communautét ${ }^{44}$; enfin, et surtout, l'audition de chaque religieux en cellule par les officiers et syndics qui souhaitent recueillir individuellement leur intention. Ainsi que le rapporte dom Coutarel, cette expérience, commencée le 6 mai, est davantage vécue par les moines comme une atteinte à leur intimité :

« On vint nous demander plusieurs fois, note-t-il, si nous étions disposés à profiter de la liberté qui nous était accordée par la nation; notre réponse fut toujours que nous en profiterions pour persévérer dans notre état de chartreux ; et on nous obligeait, chacun en particulier, de donner à cet égard notre déclaration par écrit ${ }^{45}$.

Les réponses des occupants de la maison-mère sont quasi-unanimes, à l'image de plusieurs maisons de l'Ordre qui suivent les choix dictés par leurs supérieurs ${ }^{46}: 27$ religieux de chœur $(79,5 \%), 15$ frères convers $(100 \%), 30$ frères donnés $(100 \%)$ et 14 domestiques infirmes ou hors d'état de travailler déclarent vouloir « vivre et mourir en chartreux ». 6 pères $(17,6 \%)$ demandent un sursis, 1 seul $(2,9 \%)$ veut « sortir de sa maison et se retirer religieux $\gg{ }^{47}$. Ces statistiques laissent penser qu'il y a eu concertation et débat communautaires entre les réguliers. Il faut se garder de voir dans ces attitudes un comportement spécifiquement cartusien. Dans la province des franciscains récollets de Lyon, Frédéric Meyer a observé le même désir de "fidélité ultime à l'union prônée par la règle $»^{48}$. Dom Éphrem, l'un des plus jeunes religieux de la maison (il n'a que 26 ans), est évidemment du nombre de ceux qui refusent catégoriquement de quitter le cloître. Sa déclaration, « vivre et mourir dans son état de chartreux, si Dieu le permet», masque difficilement la force d'un engagement qui redouble d'intensité entre mai et novembre, au moment

(43) AMC, 5 Hist. 22, visite domiciliaire des 2-6 mai 1790, p. 2.

(44) Les moines invoquent notamment les difficultés de circulation dans le massif, la modicité des pensions allouées par l'État et la cherté des grains «et autres denrées de première nécessité dont ils ont besoin ». Ibid., p. 17-18.

(45) AMC, n.c., Souvenirs..., n.f ${ }^{\circ}$.

(46) Le comportement est similaire dans les chartreuses bourguignonnes ou dans celle de Paris. Dominique Dinet, op. cit., p. 270 ; Bernard Delpal, art. cit., p. 158.

(47) $\mathrm{AD}$ Isère, $1 \mathrm{Q} 360$, inventaires mobiliers (1789-1793). Ces estimations corrigent les statistiques d'A.-M. de Franclieu, qui occulte délibérément la sortie d'un religieux. A.-M. DE FRANCLIEU, op. cit., I, p. 297-298.

(48) Frédéric Meyer, Pauvreté et assistance spirituelle. Les franciscains récollets de la province de Lyon aux XVII et XVIII siècles, CERCOR, Presses de l'Université de Saint-Étienne, Saint-Étienne, 1997, p. 418. 
même où les hostilités s'accentuent à l'encontre de l'Ordre dans toute la France $^{49}$. Lors de la seconde visite domiciliaire, le 26 novembre, douze jours après que l'inventaire détaillé des biens du couvent a été établi par le directoire du district de Grenoble ${ }^{50}$, le religieux se singularise et rompt avec les mots stéréotypés de ses comprofès. Il réitère sa position en déclarant aux patriotes locaux que « le cloître [est] son centre et que pour cette raison il [veut] vivre dans son état de chartreux $»^{51}$. Il est également le seul à rappeler son statut de " prêtre ", qu'il inscrit noir sur blanc à côté de sa signature.

En dépit d'une assurance délibérément provocante, le moine de Chartreuse aborde l'année suivante dans de mauvaises conditions. Le 6 avril 1791, Hilaire, procureur syndic du directoire du district, informe dom Hilarion Robinet de l'élection future d'un nouveau supérieur et de nouveaux officiers ${ }^{52}$. Quelques mois plus tôt, il avait demandé à la communauté de verser la moitié de sa caisse pour financer le traitement du clergé $^{53}$. Le révérend père est peu enclin à négocier. Pour amasser quelques liquidités, il fait procéder à l'aliénation d'une partie des biens qui lui ont été confiés par la Nation, sans se conformer aux formalités légales. Le 17 avril, comme les lois des 14 octobre et 12 décembre 1790 l'exigeaient pourtant, il fait voter avec retard un nouveau règlement conforme aux Statuts et « règles et usages » de l'Ordre, auxquels il n'espère en « rien innover ni déroger $»^{54}$. Il se prépare également à maintenir sa congrégation dans l'irrégularité et organise la visite des corps constitués en prenant conseil auprès des évêques de Vienne et de Grenoble qui, de Chambéry, dirigent l'activité des contre-révolutionnaires en Dauphinés5. Dom

(49) Pour ne prendre qu'un seul exemple, signalons qu'à la fin du mois d'août 1790 le district d'Aubenas adresse un rapport alarmant au Comité ecclésiastique pour demander un détachement de 15 hommes de troupe afin de protéger la chartreuse de Bonnefoy (Ardèche), «menacée de pillage ». AN, DXIX 101/412/12 (24 août 1790). Bernard DelPal relève d'autres cas ; art. cit., p. 151-154.

(50) Thivolet (chanoine), «Les chartreux pendant la Révolution », Bulletin de l'Académie Delphinale, $5^{\mathrm{e}}$ série, 15,1924 , p. 17-49. Les documents originaux ont disparu dans l'incendie du village de Saint-Pierre-de-Chartreuse en 1846.

(51) AMC, 5 Hist. 22, p. 168.

(52) AMC, 4 Varia $1, \mathrm{n}^{\circ} 2$, lettre d'Hilaire, procureur syndic du Directoire du district de Grenoble, à Dom Hilarion Robinet, 6 avril 1791.

(53) Soit 36000 lt en numéraire. AMC, 4 Varia 1, $n^{\circ}$ 1, lettre d'Hilaire, procureur syndic du Directoire du district de Grenoble, à Dom Hilarion Robinet, 14 décembre 1790.

(54) A.-M. De Franclieu, op. cit., I, p. 589.

(55) L'archevêque de Vienne Charles II François d'Aviau du Bois de Sanzay (1789-1798) et l'évêque de Grenoble Henri-Charles Dulau d'Allemans (1789-1802). Jean GodEL, « La génération de la Révolution (1789-1825) », dans Bernard Bligny, Grenoble. Histoire des diocèses de France, 12, Paris, 1979, p. 174-175. 
Éphrem et le reste du groupe lui renouvellent ses vœux lorsque les patriotes viennent appliquer les lois des 14 octobre et 12 décembre $1790^{56}$. Le chartreux se souvient de l'épisode avec morgue et aplomb. Il le confie à la plume de dom Jean Sallier qui le relate de manière très théâtrale, en présentant grossièrement en fond de scène le révolutionnaire dans le rôle de l'ignare effarouché :

« On ne s'en tint pas là ; on voulut nous rendre schismatique, et nous vîmes arriver peu de temps après [le 18 avril] le maire de la paroisse, ancien domestique de la Chartreuse, et qui venait accompagné de son conseil présider à l'élection que, d'après la loi, nous devions faire d'un nouveau supérieur et de nouveaux officiers. Nous nous rendîmes à la salle de la Définition pour cette cérémonie qui ne fut pas longue, parce que nous nous y étions préparés, et que les évêques émigrés que nous avions envoyé consulter à Chambéry nous avaient tracé ce que nous avions à faire dans cette circonstance. Ainsi, après la lecture du décret, nous mimes nos billets que nous tenions dans nos mains dans le vase destiné à cet effet. Ces billets contenaient simplement les noms de nos supérieurs et officiers actuels avec leurs titres. Le président avec ceux qui l'accompagnaient, extrêmement intimidés en se voyant au milieu de leurs anciens maîtres et de gens qui en savaient plus qu'eux, ne demandèrent aucune explication et ne s'aperçurent pas que le Révérend Père et le premier Procureur étaient absents, ou, s'ils s'en aperçurent, ils n'en dirent rien, et ils se retirèrent après qu'ils eurent dressé le procès-verbal de leurs opérations qui leur fut dicté par Dom Sébastien Palluis $»^{57}$.

La mort de dom Hilarion, le 4 mai 1791, le jour même où le directoire du département de l'Isère proclame la vente du « désert » et la transformation de la Grande Chartreuse en maison de réunion pour les chartreux français souhaitant y résider ${ }^{58}$, n'entame pas l'obstination de dom Coutarel, ni celle des maisons de Chartreuse, de Currière et de Chalais. Alors que les autres instituts s'éparpillent ou tentent d'obtenir des mesures dérogatoires, le 10 mai les moines, soutenus par une dizaine de réfugiés venus d'autres ermitages, portent illégalement dom Nicolas-

(56) AMC, 5 Hist. 22, Inventaires de la Chartreuse, 1790-1792, p. 280.

(57) AMC, 7 Cout 1, p. 4-6.

(58) AMC, 4 Varia $1, n^{\circ} 5$, procès-verbal du Directoire du département de l'Isère (4 mai 1791). 
Albergati de Geoffroy (1791-1801) au généralat ${ }^{59}$. Malgré la réplique énergique du Comité ecclésiastique et les ultimatums répétés des autorités révolutionnaires, cet ancien prieur de Rouen et visiteur de France-surSeine continue d'exercer impudemment sa charge jusqu'en 1792, non sans affirmer sa parfaite soumission à la 1 loi $^{60}$. Dom Éphrem le prend désormais pour modèle et le considère comme "un bon chartreux ", sévère et prompt à faire respecter l'esprit des « Statuts », davantage encore en temps de crise ${ }^{61}$. Les difficultés surviennent l'année suivante. Au printemps 1792, les deux moines sont en proie au doute.

L'occupation soudaine du monastère par les forces armées leur offre l'opportunité de lutter ensemble une dernière fois. En ce début avril 1792, on commence à entrevoir l'imminence d'un conflit avec le royaume de Savoie. Des deux côtés de la frontière, les politiques, les militaires, se préparent à la guerre. Les événements se précipitent en avril-mai, lorsque Victor-Amédée III de Sardaigne (1726-1796) interdit au nouvel ambassadeur de France de poursuivre sa route jusqu'à Turin pour y présenter ses lettres de créances ${ }^{62}$. La rupture diplomatique entre la France et le Piémont est consommée. Les émissaires français regardent dès lors la Grande Chartreuse comme un point faible dans les lignes de défense ${ }^{63}$. Depuis les premiers jours de mai, ils soupçonnent fortement les pères de Chartreuse d'intelligence avec le « roi des Marmottes » et l'évêché de Chambéry, qui relève directement du pape depuis ses origines en 1779. Les fils de saint Bruno sont notamment suspectés de constituer des stocks d'armes et de vivres pour les armées du roi de Sardaigne et pour tous les ennemis de la Révolution réfugiés en Savoie. Jusqu'alors modéré et relativement bienveillant envers les chartreux, le directoire du département de l'Isère s'en inquiète. Le 6 mai, il commande aux ingénieurs des ponts-et-chaussées de p. 168

(59) [Anon.], La Grande Chartreuse par un chartreux, 16 édition, Bellegarde, 1991,

(60) À la fin 1791, il rend un compte d'exploitation des biens gérés par les chartreux, probablement biaisé par rapport à la réalité. AD Isère, 1 Q 408 (1790-an III).

(61) AMC, n.c., Souvenirs..., p. 2.

(62) Jean Nicolas, La Révolution française dans les Alpes, Dauphiné et Savoie, 1789-1799, Toulouse, 1989, p. 154-155.

(63) Le territoire est particulièrement exposé depuis la perte de Pignerol (1697) et des vallées transalpines (1713). La perméabilité de la frontière, connue de tous, autorise depuis plus d'un siècle des commerces illégaux entre les riverains. René FAVIER, Les villes du Dauphiné aux XVI et XVIII $e^{2}$ siècles, Presses Universitaires de Grenoble, Grenoble, 1993, p. 140-148; Jean DescotesGENON, «"Ces paysans grossiers voisins de la frontière et... qui passent en Savoie”. La contrebande sur le Guiers vue par les intendants du Dauphiné au XVIII siècle ", La Pierre et l'Écrit, Grenoble, Presses Universitaires de Grenoble, 2004, n 15, p. 163-185. 
Grenoble de restaurer les communications entre Voreppe et la Grande Chartreuse et de « réparer tout de suite les endroits de la route qui pourroient apporter des obstacles à la marche de l'artillerie $\aleph^{64}$. Le même jour, le commandant des armées de Grenoble donne ordre de transporter de Valence (Drôme) deux pièces d'artillerie " de quatre » en Chartreuse. C'est dans ce climat tendu que circulent des rumeurs sur la présence d'agents sardes prêts à envahir avec leurs armées le territoire frontalier, depuis l'Arve jusqu'au Guiers en passant par la Chartreuse. Le district de Grenoble, où des sociétés populaires actives réclamaient la stricte application des décrets que le roi refusait de ratifier, s'en émeut dans ses délibérations du 18 mai. Le vice-président André Amar, futur représentant en mission de l'Isère $^{65}$, et ses collègues exigent la dissolution du foyer rebelle de Chartreuse sous huitaine et le transfert des religieux souhaitant opter pour la vie commune à la Sylve-Bénite (Isère) ou à Durbon (HautesAlpes), deux chartreuses des cantons de Virieu et d'Aspres-sur-Buëch ${ }^{66}$.

L'affaire est réglée en quelques jours. Le 19, le général Anne-Pierre de Montesquiou-Fezensac (1739-1798), qui commandait l'armée du Midi, est sur le point d'envoyer un détachement de troupes de ligne et de volontaires nationaux dans les communes voisines de Saint-Pierre-de-Chartreuse et de Saint-Laurent-du-Pont pour « s'assurer du poste de la Grande Chartreuse ${ }^{67}$. Le même jour, le directoire du département décide l'évacuation du monastère ${ }^{68}$. Le 20, les pères de Chartreuse accueillent trois émissaires du district et 400 hommes de troupes chargés de mettre à disposition de l'administration le mobilier, les denrées et toutes les marchandises du couvent ${ }^{69}$. Conscients d'un éventuel revirement des moines, les commissaires Réal, Amar et Giroud ne les informent du but principal de leur mission que le lendemain. Ainsi que le rapporte dom Éphrem, l’ordre les plonge « tous dans la consternation, et il fut décidé qu'on enverrait de suite dom Ambroise Burdet et dom Sébastien Palluis à Grenoble pour le faire révoquer: ce qu'ils obtinrent, après avoir essuyé dans les rues les

(64) $\mathrm{AD}$ Isère, L 107, correspondance du Directoire du département, f $232 \mathrm{v} .-233 \mathrm{r}$.

(65) Florent Robin, Les représentants en mission dans l'Isère. Chronique d'une Terreur "douce » (1793-1795), Paris, 2002, p. 29-33.

(66) AMC, 4 Varia 1, n 7, délibération du district de Grenoble, 18 mai 1792.

(67) $\mathrm{AD}$ Isère, L 107, correspondance du Directoire du département, $\mathrm{f}^{\circ} 261 \mathrm{r}$.-v.

(68) AMC, 4 Varia 1, $\mathrm{n}^{\circ}$ 8, délibération du Directoire du département, 19 mai 1792.

(69) AMC, 4 Varia 1, $n^{\circ} 9$, lettre du procureur syndic Hilaire à Clappier, directeur des droits incorporels, 20 mai 1792. 
huées de la populace qui leur courait après $»^{70}$. Après avoir lu le rapport de Giroud, le directoire du département lave finalement les chartreux de tout soupçon le 24 mai. Il leur confie même la gestion des forêts et des forges, « objets précieux » en temps de guerre, et missionne les commissaires du directoire d'assigner « telle partie de la maison qu'ils jugeront convenable pour les religieux, les frères et les domestiques, en prélevant [...] la quantité de logement suffisante pour une garnison de six cents hommes $\gg^{71}$. Si cette décision ne rassure guère les populations des environs, toujours sujettes aux peurs les plus irraisonnées ${ }^{72}$, elle ouvre pour les chartreux le temps de la coexistence avec les soldats de la patrie. Elle marque aussi la transformation du monastère en forteresse par Montesquiou.

Pour aller plus loin dans le commentaire à ce niveau d'observation, il faudrait bien sûr savoir comment les militaires vécurent leur séjour ${ }^{73}$. L'absence de source dans les archives révolutionnaires l'interdit malheureusement. Il est en revanche certain que les témoignages des chartreux, surtout celui de dom Coutarel, nous renseignent sur la perception du trouble produit par l'immixtion d'un monde profane et martial dans le cloître. Si dans sa lettre du 31 mai dom Nicolas-Albergati de Geoffroy parle « d'une bourrasque » pour suggérer au prieur de Paris l'arrivée des troupes qui «occasionnent tant de dérangements » ${ }^{74}$; dom Éphrem devient prolixe lorsqu'il évoque la réception des militaires vers une heure de l'après-midi ${ }^{75}$. L'incompréhension entre les soldats et le chartreux ne cesse d'ailleurs de croître entre le 20 mai et le 10 juillet. Dans ses Souvenirs, le moine se plait à évoquer les vexations que le détachement armé

(70) Ibid., p. 9. Les Grenoblois reprochaient aux chartreux le port du costume religieux, bien avant son interdiction par la Convention (10 août 1792).

(71) AMC, 4 Varia 1, $\mathrm{n}^{\circ} 10$, délibération du Directoire du département de 1'Isère, 24 mai 1792.

(72) Dans la commune de Saint-Laurent-du-Pont, « le bruit s'étoit répandu que deux cents Piémontois [et] deux pièces de canon nouvellement envoyés par le duc de Savoye, venoient renforcer le poste des Échelles » (25 mai 1792). AD Isère, L 68, procès-verbal du Directoire du département de l'Isère, p. 3345-3359.

(73) Le résultat des dépouillements exhaustifs effectués dans les fonds révolutionnaires des archives départementales de l'Isère (séries L et Q) ne permet pas de compléter l'information comme on le souhaiterait.

(74) Le Révérend Père note qu'il est « obligé d'interrompre [son] travail » à chaque instant. A.-M. De Franclieu, op. cit., I, p. 313.

(75) «S'étant arrêtés dans la basse-cour, on s'empressa de leur servir du pain, du fromage et du vin. Lorsqu'il fut question de les loger, on leur offrit l'Allée des Cartes et les autres corridors, mais ils n'en voulurent point, et demandèrent les clefs des salles et des chambres qu'il fallut leur livrer. Les frères qui en occupaient une partie, en enlevèrent de suite leurs effets et les portèrent dans les cellules vacantes du cloître qu'ils habitèrent jusqu'à notre sortie ». AMC, 7 Cout. 1, p. 8. 
fait endurer aux réguliers pour mieux le discréditer et lui faire endosser le costume du «méchant». Selon lui, l'existence spirituelle et matérielle des pères se dégrade peu à peu. Pour le moine, tous les cadres de la vie cartusienne sont touchés : le réfectoire, où les patriotes « $\mathrm{s}[\mathrm{e}] \mathrm{f}[\mathrm{ont}]$ servir depuis le matin jusqu'à bien avant dans la nuit », les salles, les chapelles, l'église et même les cellules. Les temps sont perturbés également : les offices de jour et de nuit, l'appel de Mâtines et Laudes lancé par le père « excitateur», mais aussi le spaciment, la promenade hebdomadaire durant laquelle les piquets présents " dans toutes les avenues du cloître » accompagnent les pères de crainte qu'ils n'enlevassent « le[ur] prétendu trésor ». Suivant dom Éphrem, les soldats qui résidaient dans les pavillons massifs de France, de Bourgogne, d'Italie et d'Allemagne, dans l'aile d'honneur du couvent, ne ménagent pas leur peine à l'encontre des symboles chrétiens. Les images et objets de dévotion sont détournés. Les « tableaux de piété » sont décrochés de leurs cimaises, couverts " d'immondices » puis jetés par les fenêtres. La vaisselle liturgique est utilisée pour manger à table. Des religieux sont brutalisés, d'autres sont poursuivis dans le cloître par des militaires sabres au clair ${ }^{76}$.

Jusqu'à l'entrée des Français en Savoie (22-30 septembre 1792), la venue de plusieurs régiments de soldats de l'Ardèche et de l'Isère, accompagnés parfois de leurs concubines, provoque un réel émoi dans la communauté. On le perçoit davantage lorsque l'on sait que les moines refusaient d'appliquer la dispense papale du 19 mars 1792 qui les autorisait pourtant à ne plus observer l'intégralité des «Statuts » ${ }^{77}$. Dom Coutarel indique sans plus de précision «le désagrément [qu'il avait] quelquefois [de voir des femmes à] l'église pendant les offices » et dans le cloître, où elles étaient hébergées avec les hommes dans des cellules vacantes. Par crainte de représailles les chartreux se taisent, mais ridiculisent discrètement les révolutionnaires qu'ils assimilent, en forçant férocement le trait, à des soudards incultes et bêtas. Lorsqu'il condamne l'activité des sentinelles qui mutilent les tableaux des fondateurs des maisons, dom Éphrem souligne que seul celui de Philippe le Hardi fut épargné, «parce qu'il était représenté avec un bonnet rouge ${ }^{78}$ ! Cette situation incertaine ne devait pas survivre au choc de l'automne 1792.

(76) AMC, 7 Cout. 1, p. 9-10.

(77) Conformément aux vœux du Général des chartreux, les membres sortis de l'Ordre pouvaient bénéficier des dispenses de Pie VI. La lettre imprimée qu'il leur adresse est intégralement reproduite par A.-M. DE Franclieu, op. cit., I, p. 584-587.

(78) AMC, 7 Cout. 1, p. 10-18. 
Le sort de la communauté est réglé dans l'été. L'Assemblée avait décrété son départ effectif les 16 et 17 août $^{79}$. Le 10 septembre, les pères sont informés par le vice-procureur Giroud de l'évacuation prochaine, qui touche déjà d'autres familles de réguliers - les capucins de Vienne sont expulsés le lendemain, les autres conventuels se dispersent avant même qu'ils y soient forcés. Celle des chartreux est arrêtée au $1^{\text {er }}$ octobre $^{80}$. Le 23, Margot, commissaire du directoire présent en Chartreuse, s'occupe des derniers préparatifs et le lendemain, les administrateurs du district de Grenoble félicitent Bigillon, maire de Saint-Pierre-de-Chartreuse, de n'avoir pas délivré des passeports pour l'étranger aux religieux qui souhaitaient prendre la fuite ${ }^{81}$. Les débats pour la survie du monastère ou sa suppression entre les membres du directoire du département et du directoire du district de Grenoble sont animés. L'intervention du directoire du département, qui décide le $1^{\text {er }}$ octobre d'affecter les chartreux à la conservation de la propriété nationale, et la pétition de l'économe dom Palluis, jouant captieusement le même jour de la rhétorique révolutionnaire pour témoigner son « zèle pour le bien public », ne font que repousser l'inéluctable ${ }^{82}$. Le jour de la saint Bruno 1792, le directoire du district de Grenoble nomme Giroud commissaire à la Grande Chartreuse à la place de Margot ${ }^{83}$. La communauté est finalement dissoute le 14 octobre. Trois pères quittent l'habit monastique "après la grand'messe » et revêtent des vêtements séculiers pour se rendre à Voreppe, puis à Lyon. Jusqu'en 1794, le destin individuel de dom Éphrem échappe grandement à l'archive, autant qu'à la sagacité de ses poursuivants. Les documents n'ont pas tous été conservés. Certains ont été brûlés par le moine, qui souhaitait effacer toute trace de son activité. D'autres, d'époque révolutionnaire, après qu'ils ont été restitués aux chartreux par l'État dans la décennie 1820-30, ont été détruits lors de l'expulsion de 1903 ou plus récemment dans les années $1960^{84}$. Retracer le parcours clandestin de dom Coutarel n'est pas toujours facile, utiliser la documentation disponible ne l'est guère davantage. La nature

(79) AD Isère, 1 Q 360, inventaires mobiliers (1789-1793).

(80) AMC, 4 Varia 1, n 11, lettre de Giroud au Révérend Père, 10 septembre 1792.

(81) AMC, 4 Varia 1, $\mathrm{n}^{\circ} 13$, correspondance des membres du District de Grenoble, 24 septembre 1792 .

(82) AD Isère, 1 Q 360 ; AMC, 4 Varia 1, n 14, pétition de dom Palluis au Directoire du département de $1^{\prime}$ Isère, $1^{\text {er }}$ octobre 1792.

(83) AMC, 4 Varia 1, $n^{\circ} 15$, délibération du Directoire du district de Grenoble, 6 octobre 1792.

(84) Sur l'expulsion, lire notamment : René BouRgeors, L'expulsion des Chartreuse. 29 avril 1903, Presses Universitaires de Grenoble, Grenoble, 2000, p. 71 et sqq. 
même des Souvenirs dictés par le religieux et les témoignages oraux qui ont été recueillis par écrit après sa mort parmi ses contemporains invitent à la plus grande prudence. Ces informations biographiques, nous avons voulu les confronter aux renseignements beaucoup plus fiables que nous avons récoltés dans différents papiers : les procès-verbaux de l'administration centrale du département de l'Isère, les comptes rendus des administrateurs de Chartreuse, les registres d'état-civil de différentes communes ou encore les registres d'écrous de Grenoble ${ }^{85}$.

\section{Le missel et le « Statut » (1792-1802)}

Le 17 octobre 1792, les derniers chartreux évacuent la maison mère. 29 pères, 15 convers et 23 donnés $^{86}$ refusaient toujours de prêter le serment dit de « Liberté, égalité » réclamé à tout ecclésiastique le 14 août. La législation du 26 ne laissait guère d'alternative aux plus récalcitrants : fuir le pays ou rester illégalement en France, au risque de connaître la mort sur les pontons ou l'échafaud (le sort de $24,1 \%$ des pères de Chartreuse qui, pour beaucoup, recherchèrent le « martyre »). Après quelques hésitations, dom Coutarel se distingue du reste de la communauté. D'abord, il s'interdit de quitter le territoire et de grossir les rangs des 47 jeunes profès français qui tentèrent l'aventure collective à l'étranger ${ }^{87}$. Il ne suit pas le révérend père qui partit avec trois moines par-delà les Alpes pour se placer sous la protection de la curie romaine ${ }^{88}$. Il ne chemine pas non plus vers la Suisse, du côté de la Part-Dieu (une maison de la province de Chartreuse) et de la Valsainte, où tout un groupe prenait congé dans une communauté de cisterciens réformés dirigée par Augustin de Lestrange (1754-1827) ${ }^{89}$. Il refuse également de rejoindre sa famille (seuls $6,9 \%$ des pères optent pour cette solution) et d'augmenter la masse des

(85) Régis Bertrand s'est heurté au même problème quand il conduisait ses investigations sur l'action clandestine du chartreux Joseph Martinet (1750-1795) à Marseille. Cf., Régis BerTRAND, « Dom Joseph de Martinet (1750-1795) et son action clandestine à Marseille pendant la Révolution », Analecta Cartusiana, nouvelle série, II, n 4, juillet-décembre 1990, p. 173-189.

(86) AD Isère, L 638, État des religieux, frères convers et donnés de la Grande Chartreuse et ses dépendances existans le 24 septembre 1792.

(87) Dom Augustin Devaux, art. cit., p. 142.

(88) Ils se réfugient à Rome, puis à Bologne. Archives secrètes du Vatican, Segr. Stato, Emigrati Riv. Francese, $40, \mathrm{f}^{\circ} 100 \mathrm{r}$.

(89) Jacques Rime, « La Part-Dieu », Helvetia sacra, III.4, Bâle, 2006, p. 190 et 200 ; Patrick Braun, « La Valsainte », ibid., p. 255 ; Augustin-Hervé LaffaY, Dom Augustin de Lestrange et l'avenir du monachisme (1754-1827), collection Histoire religieuse de la France, 12, Paris, Cerf, 1998, p. 53-130 et G. Guerout, « La communauté de la Trappe face à la Révolution : 13 février 1790-3 juin $1792 »$, Cîteaux, 40, 1989, p. 376-478. 
prêtres réfractaires retirés dans le canton de Ruynes-en-Margeride, dans les communes de Faverolles et de Bournoncles ${ }^{90}$. L'option n'était pourtant pas déraisonnable. En 1790, son oncle Antoine s'était résolu à prêter le serment de fidélité à la Constitution civile du clergé et ne fut inquiété par les autorités qu'en nivôse an II (12.1793-01.1794), quand il dut remettre ses lettres de prêtrise et abdiquer ${ }^{91}$. Dom Éphrem aurait pu aussi trouver refuge chez ses frères : Jean-Antoine et Guillaume avaient les moyens de lui offrir l'hospitalité dans la ferme paternelle. Les deux frères appartiennent à cette catégorie de paysans aisés qui rachètent une partie des biens nationaux de Lorcières, dans un département où la faible propriété de l'Église échappe aux ruraux les moins fortunés ${ }^{92}$. Les cadets Coutarel, officiers municipaux, participent encore aux assemblées primaires du canton de Ruynes en juin 1791 et août $1792^{93}$. Comme l'observent Raymonde Monnier et Philippe Daumas à partir d'exemples concernant de nombreuses communes de la région parisienne, « la participation régulière à la vie politique fut, en banlieue, comme à Paris, le fait d'une minorité ». La « direction des communes reste aux mains des personnalités qui dominaient déjà le village dans les dernières années de l'Ancien Régime $»^{94}$. Tel est aussi le cas à Lorcières. Après 1789 , la position sociale de la famille Coutarel y est toujours dominante. Elle inspirait sans doute le respect dans un canton peu touché par les troubles religieux et caractérisé par la résistance passive de ses populations face à la déchristianisation $^{95}$. Les déclarations recueillies en ventôse an II (02.1794-03.1794) pour dénombrer les effets appartenant aux familles de suspects reconnus

(90) Pierre Chassang, « Le clergé de canton de Ruynes-en-Margeride pendant la Révolution française », Revue de la Haute-Auvergne (RHA), 54, 1990, p. 1-56.

(91) AD Cantal, L 648, État nominatif des curés et vicaires du district de Saint-Flour qui ont prêté le serment ordonné par le décret du 27 novembre $1790, \mathrm{f}^{\circ} 1 \mathrm{v}$. Il rétracte son serment; il est recherché le 3 germinal an II. AD Cantal, L 592, procès-verbaux des séances secrètes du conseil du district de Saint-Flour (11 ventôse an II-29 floréal an III), f $43 \mathrm{v}$.

(92) AD Cantal, 1 Q 122, adjudications définitives des biens corporels de première origine, district de Saint-Flour (19 mai-1 ${ }^{\text {er }}$ août 1791), f 599 r-600v.

(93) AD Cantal, L 117, élections, district de Saint-Flour, pièces nos 33,35 et 37.

(94) R. Monnier, «La politisation des paroisses rurales dans la Région parisienne », La Révolution française et le monde rural, Paris, 1989, p. 430 ; Philippe DaUmas, Familles en Révolution. Vie et relations familiales en Île-de-France, changements et continuités (1775-1825), Presses Universitaires de Rennes, Rennes, 2003, p. 68-71.

(95) Anouk Trocellier, Les troubles religieux dans le district de Saint-Flour de 1790 à l'an II, Mémoire de maîtrise [Philippe Bourdin, dir.], Université Blaise Pascal, Clermont-Ferrand II, [s.1.], 1995, dactyl., p. 27-28, 73-77, 137-156 ; Jonathan R. DALBy, Les paysans cantaliens et la Révolution française (1789-1794), Université Blaise Pascal, Clermont II, Publications de 1'Institut d'Études du Massif Central, fasc. XXXVI, Aurillac, 1989, p. 137-146. 
ennemis de la République, en donnent un aperçu. Dans le canton de Ruynes, Jean-Antoine et Guillaume affirment qu'ils ne connaissent ni émigré ni prêtre réfractaire, ni père et mère d'insermenté ${ }^{96}$. Leur maisonnée était pourtant concernée par les mesures radicales du Comité de salut public ordonnant la redistribution des terres aux indigents. Comme la grande majorité des foyers cantaliens visés par les décrets de ventôse, ils ne furent pas inquiétés ${ }^{97}$. On est bien entendu en droit de se demander pourquoi dom Éphrem n'a pas gagné un asile si sûr.

Comme il le confie à dom Jean Sallier lors de leurs entretiens, il prend en octobre 1792 la résolution de ne jamais quitter les environs du monastère ${ }^{98}$. Jusqu'en 1794, ses cachettes et son itinéraire sont connus. Le chartreux réside successivement dans d'anciennes possessions ou seigneuries cartusiennes, voire dans des villages du massif préalpin de la Chartreuse situés à quelques encablures du monastère: la grange de Chartrousette, le ménil du Guier, Saint-Joseph-de-Rivière, Currière, le clocher de la Correrie, la Grande Chartreuse, le « désert » de Chalais, les forêts d'Arpizon, le hameau de Provenches, le petit bois de Currierette. L'absence de villes ou de gros bourgs ${ }^{99}$, l'éparpillement des hameaux et la présence de zones fortement boisées coupées de la plaine durant huit mois de l'année par des chutes de neige toujours précoces' favorisent la vie clandestine. Dom Coutarel bénéficie également d'un atout de taille par rapport aux révolutionnaires : il dispose d'une très bonne connaissance du terrain, qu'il met à profit. Si on la compare avec les cartes panoramas cartusiennes de la fin du XVII ou du début du XVIII siècle qui couvrent, par secteurs, la totalité du « désert $»^{100}$, la géographie de ses refuges coïncide sensiblement avec les anciennes limites de spaciment ou de possession du monastère.

(96) AD Cantal, 1 Q 406, inventaire et séquestre du mobilier et des effets appartenant aux prêtres réfractaires et aux pères et mères d'émigrés de la commune de Lorcières, an II.

(97) Jonathan R. DALBy, op. cit., p. 138.

(98) Son engagement découle du souvenir d'une révélation d'un vicaire de Chartreuse des $\mathrm{XII}^{\mathrm{e}}$ et $\mathrm{XIII}^{\mathrm{e}}$ siècles, dont les paroles sur son lit de mort avaient été conservées de génération en génération jusqu'à la Révolution : "La Grande Chartreuse ne serait abandonnée, [...] les anges l'habiteraient plutôt », AMC, n.c., Souvenirs..., f 7 r. On retrouve une variante inscrite sur la première de couverture d'un missel cartusien de 1900 : «stabilitas ordinis Cartusiensis mundi duratis (parole de N.S. J.C. à dom Jean, vicaire de la Grande Chartreuse de 1171 à 1234 », AMC, 2 Bre 27.

(99) René FAVIER, op. cit., p. 44-54.

(100) AD Isère, 4 H 267. 
Figures V, VI, VII : Les refuges d'Arpizon et de Chartrousette d'après la Reproduction des cartes du Massif de la Chartreuse dressées par les Révérends Pères Chartreux en 1688.

Cette perspective cavalière de la partie Ouest du « désert » de Chartreuse, où figure le couvent de la Grande Chartreuse en contrebas des lignes de crêtes des rochers des Molières, du Solitaire et d'Arpison, donne une vue de la clairière d'Arpison (alt. 1418 m.) et de la grange cartusienne de Chartroussette (alt. 1013 m.), où dom Éphrem se réfugia tour à tour en 1793. Les deux haberts qui dominaient le monastère n'étaient desservis que par des mauvais chemins qui serpentaient dans la montagne à travers des forêts denses de résineux. L'isolement des lieux se trouvait renforcé par l'abondance des neiges, qui ne fondaient qu'autour du mois de mai. Le chartreux bénéficiait d'un panorama imprenable sur la Grande Chartreuse, d'oratoires nombreux qui constellaient le paysage, et pouvait ainsi s'adonner à ses activités tout en surveillant les allées et venues de ses poursuivants, pour éventuellement prendre la fuite.

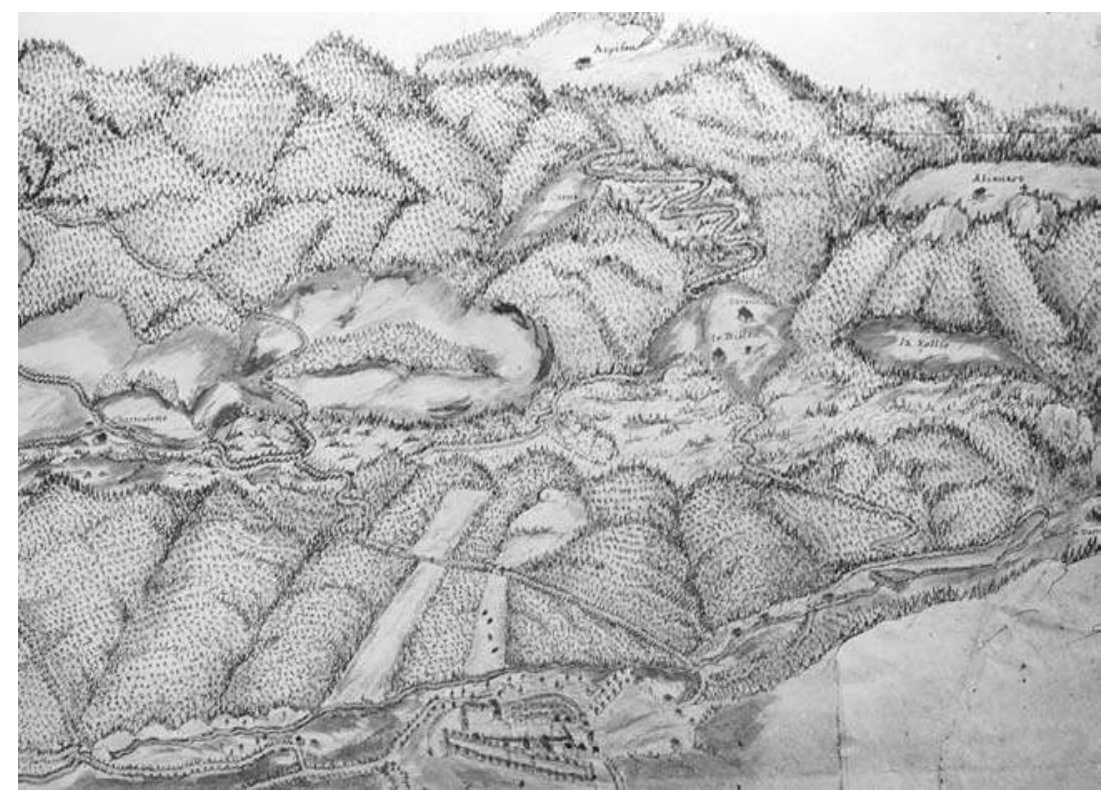



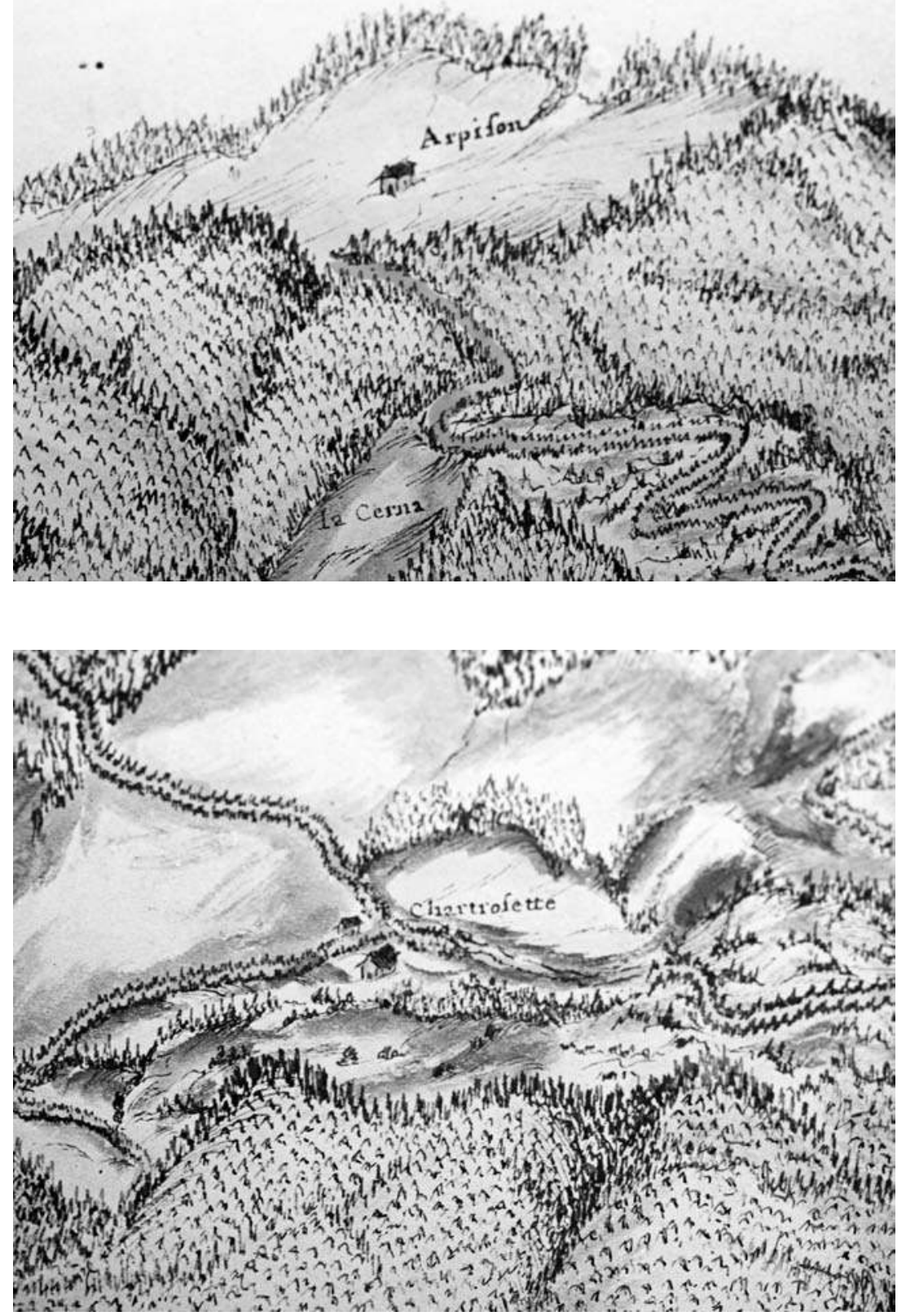

(C) $\mathrm{AMC}, 9 \mathrm{MCA} 7$

(C) Archives de la Grande Chartreuse, 2008. 

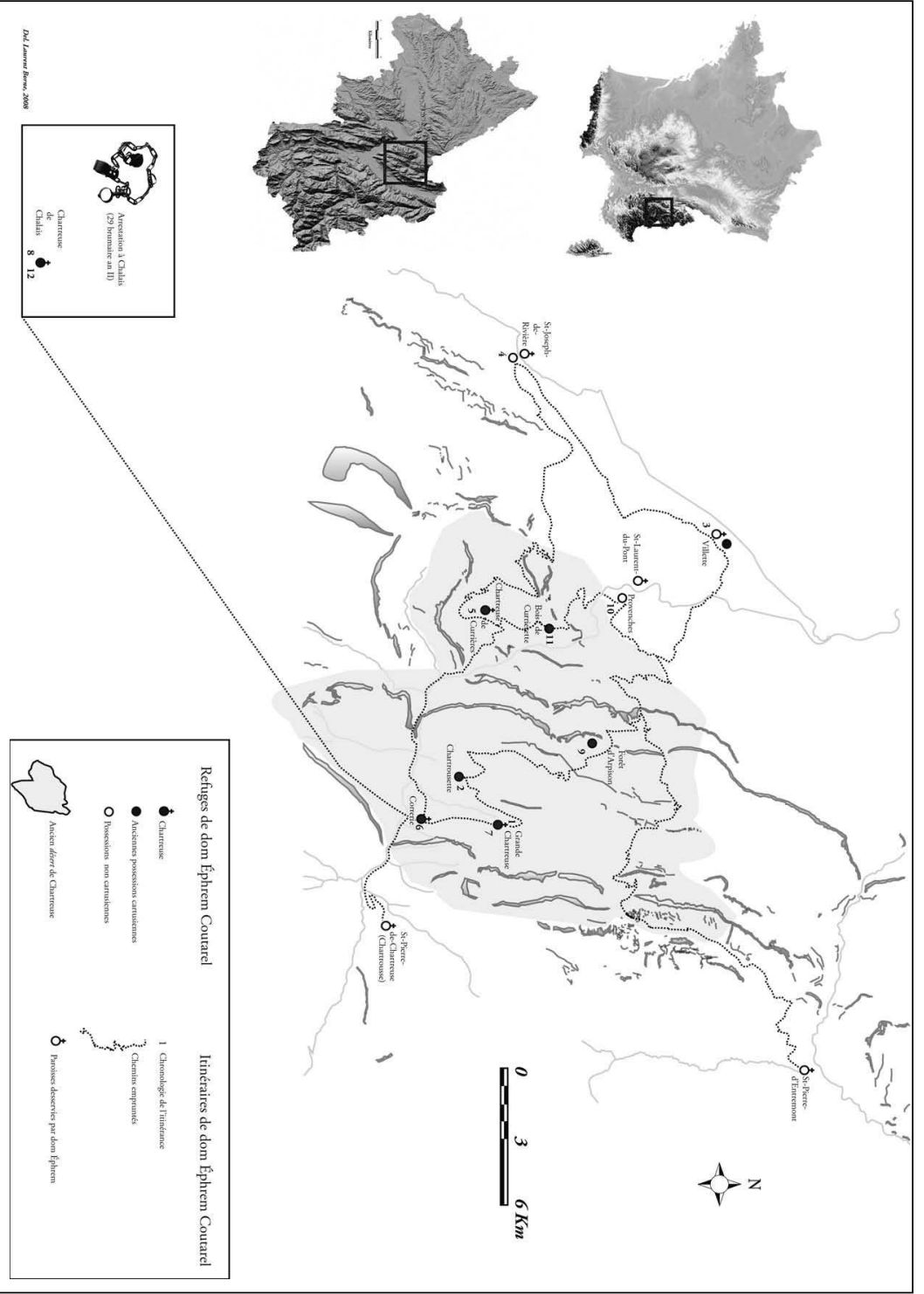

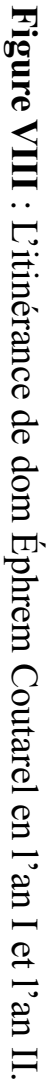


Sa mise en sûreté s'inscrit encore dans un environnement humain complice. Jusqu'en juillet, il se cache au monastère avec la connivence de quatre chartreux qui s'étaient vus confier par la Nation la régie des biens cartusiens, le 26 octobre $^{101}$. Le " rusé coquin » dom Palluis, qui travestissait la comptabilité du couvent et faisait procéder à la vente illégale des biens nationaux, dom Blanc, qui dirigeait la chartreuse de Currière et qui veillait sur un gardien manchot et sur un chartreux « entièrement aliéné », lui procurent assistance ${ }^{102}$. Au mépris de la loi, les pères gardent « [en Chartreuse] tout le monde qu'il leur a été possible de garder, et notamment chacun leur domestique personnel et beaucoup de frères ou autres individus » qui n'étaient pas compris dans le projet d'organisation que le régisseur civil Giroud avait élaboré ${ }^{103}$. À en croire Giroud, qui alerte les autorités en dénonçant « l'esprit de fanatisme, l'esprit de l'ancien ordre, l'esprit en un mot le plus aristocratique » de la communauté, 4 pères et 14 frères convers ou laïcs conservent le mode de vie cartusien « qui s'observe avec autant de rigueur que lorsque cette maison existoit dans toute sa splendeur $»^{104}$. Dom Coutarel, dont la physionomie était mal connue en raison du faible nombre de personnes qui avaient pu l'entrevoir avant la Révolution, profite sans doute de son statut de chartreux pour se fondre dans la masse et préserver son anonymat. Cette conduite n'est pas rare. À Marseille, le chartreux dom Joseph de Martinet use du même subterfuge pour résider dans une maison de la rue Thubaneau, pour ainsi dire en face du club des Jacobins ${ }^{105}$. Dom Éphrem doit quitter le couvent le 21 juillet, lorsque conformément à l'arrêté du directoire du département du 10 mai et à la lettre circulaire du ministre de l'Intérieur Garat (1749-1833) du 17 juin, les commissaires du directoire du district de Grenoble ordonnent l'arrestation des chartreux qui refusaient toujours de prêter le serment dit de «liberté-égalité » ${ }^{106}$. Dom Sébastien Palluis, procureur de Meylan, dom Emmanuel Rivière, coadjuteur de Chartreuse, et dom [Jean] Thadée Forestier, vicaire de Chartreuse, sont conduits à Grenoble, puis incarcérés

(101) AD Isère, 1 Q 360.

(102) AD Isère, L 638, lettre de Giroud au Directoire du département de l'Isère (27 janvier 1793).

(103) AD Isère, L 638, demande de secours (21 juillet 1793).

(104) AD Isère, L 638, lettre de Giroud au Directoire du département de l'Isère (21 juillet 1793).

(105) Régis BERTRAND, art. cit., p. 177.

(106) AD Isère, L 638, arrêt du Directoire du département de l'Isère (10 mai 1793). 
à la Conciergerie et à la Visitation de Sainte-Marie-d'En-Haut ${ }^{107}$, où ils retrouvent deux chartreux de la Sylve-Bénite sous les verrous ${ }^{108}$.

Peu disposée à relayer la politique religieuse de l'État tout au long de la Révolution ${ }^{109}$, la population foncièrement catholique et royaliste des environs secourt dom Coutarel. Elle ne nourrit plus de ressentiment contre la puissance sociale et foncière des chartreux, et ne fait plus grand cas de leur opposition entre 1772 et 1778 pour le calcul de l'assiette des redevances seigneuriales ${ }^{110}$. Durant sa période d'errance, le réseau clandestin de dom Éphrem paraît infaillible. Jusqu'au printemps 1793, le chartreux n'attire pas l'attention des autorités et ne figure pas sur la « liste des personnes notoirement suspectes $\gg$ du département ${ }^{111}$. Le moine est notamment protégé par d'anciennes familles de Villette, de Saint-Laurent-du-Pont et de Saint-Joseph-de-Rivière. Il séjourne d'abord chez des hommes. Il fait la connaissance de Jean-Louis Gaillard, vicaire insermenté de Saint-Laurentdu-Pont, chez les cabaretiers de Villette, Jean et Maurice Passet (25.08.176118.03.1846).LemenuisierFrançoisCharvet(1750- $\dagger$ ?)deSaint-Laurent-du-Pont, réputé pour héberger de nombreux prêtres réfractaires ${ }^{112}$, Claude Charvet, ancien domestique des chartreux ${ }^{113}$, le dissimulent dans une armoire à double fond. Le notaire de Saint-Laurent Margot et son fermier Claude Satre-Duplessis, " dévoués depuis longtemps aux intérêts des ci-devant chartreux $»^{114}$, et les Charrat de Saint-Joseph-de-Rivière, deviennent ses principaux alliés ${ }^{115}$. De la même manière, les femmes jouent un rôle déter-

(107) Le procureur de Chartreuse dom Ambroise Burdet prête le serment. Les frères également. AD Isère, L 638, procès-verbal de Pierre Giroud et Jean-François Cros (28 juillet 1793), f 2 2r.-v.

(108) AD Isère, L 226, police générale, registre des écrous de Sainte-Marie-d'En-Haut (1793-an III), fo 1 r.

(109) Les Laurentins contraignent le procureur syndic de la commune à rouvrir l'église, à restituer les cloches et à faire reprendre l'exercice du culte en messidor an III ; l'année suivante, 25 hommes de division doivent disperser les « attroupements séditieux » opposés à l'enlèvement des signes extérieurs du culte (28 pluviôse en IV). AD Isère, L 91, fo180r. ; Joseph Mollin, Saint-Laurent-du-Pont, Saint-Genix-sur-Guiers, 1966, p. 97-98.

(110) Bib. mun. Grenoble, O 12286-87 ; U 344 et U 3261.

(111) AD Isère, L 226.

(112) A.-M. De Franclieu, op. cit., II, p. 102. En septembre 1792, ils représentent $30 \%$ des effectifs du district de Grenoble. Timothy Tаскетт, La Révolution, l'Église, la France. Le serment de 1791, Paris, 1986, p. 380.

(113) A.-M. de Franclieu, op. cit., I, p. 482.

(114) AD Isère, 1 Q 350. Ils seront incarcérés pour s'être compromis en venant à l'aide des chartreux (23 brumaire an II).

(115) Il s'agissait d'amis de l'Ordre, peut-être d'anciens domestiques du couvent, comme Charvet, ce que nous n'avons pas vérifié encore. Le seul document précisant les noms et âges des domestiques de Chartreuse est très incomplet. Il ne comptabilise que les infirmes et les vieillards (14) présents au couvent lors de la première visite domiciliaire de 1790 , ce qui représente à peine $18 \%$ de l'effectif total des employés de 1789 (76 ouvriers). AMC, 5 Hist. 22, p. 33 ; AD Isère, L 638 (an XIII). 
minant. Elles hébergent le fugitif, le ravitaillent - la mère Charvet lui fait porter de la nourriture -, le préviennent et le dérobent en cas de danger. Avec leur concours, le chartreux échappe en 1793 à une perquisition des gendarmes à Villette, en se camouflant dans une malle ${ }^{116}$.

En échange de cette aide, dom Éphrem rend quelques services. Il dit la messe, baptise les enfants, bénit les mariages, visite les malades, confesse les fidèles à Saint-Laurent-du-Pont, Saint-Pierre-de-Chartreuse (Chartrousse), Saint-Pierre-d'Entremont et Villette. Avec sa pierre d'autel, sa pyxide et ses saintes huiles, il parcourt la montagne en habit de chartreux, qu'il ne quitte pas durant ses allées et venues. Peu préparé au ministère clandestin, il adapte la liturgie de Chartreuse et son discours à ses ouailles en puisant dans la classique et souvent reéditée Medulla theologica de l'évêque de Rodez Louis Abelly (1664-1666), dont il conservait par devers lui un exemplaire ${ }^{117}$. Ses sermons dans les bois de Currierette ne nous sont malheureusement pas parvenus. Le décompte des baptêmes, mariages et décès inscrits dans les registres de Saint-Pierre-de-Chartreuse (Chartrousse), entre l'an I et l'an III (1792-1794), permet cependant de donner un bref aperçu de son activité 118 : 48 baptêmes, 22 mariages et 30 décès dans une localité où le moine se plait à noter dans les livres de catholicité que « la population de ce pays ne se livra pas aux excès d'un patriotisme peu réfléchi $»^{119}$. Dom Éphrem participe encore à des veillées chez la famille Charvet, qui comprenait de nombreux adultes et une quinzaine d'enfants. Par les enquêtes commandées à l'abbé Charvet de Villette par l'Ordre en 1866, le comportement du chartreux lors de ces réunions est sommairement connu :

«Les filles, à l'époque où le Père dom Éphrem prenait part à ces réunions devoient avoir de 15 à 25 ans. Jamais le bon père ne s'est départi de la gravité de ses paroles quoique parfois il eût des saillies de langage très spirituelles $»^{120}$.

Dans l'été 1793, dom Coutarel retourne à la Correrie, à Chalais, puis au couvent, quand le réseau de surveillance se resserre autour de lui ${ }^{121}$. Profitant de

(116) AMC, 7 Cout. 1, Souvenirs..., p. 7-9.

(117) Les deux volumes de l'édition de 1663 portent l'ex-libris de dom Éphrem Coutarel : «ad usum d. Ephrem commorantis in eremo Calesii anno Domini 1793 », AMC, 3 Cout. 1.

(118) AD Isère, 5 E 443/3 et 5 E 443/7.

(119) «Au milieu de tant d'horreurs dont les méchants couvrirent la France pour y amener le désordre, la population de ce pays ne se livra pas aux excès d'un patriotisme peu réfléchi ; on les força comme ailleurs à fermer leurs églises ; mais on vit souvent les paroissiens assemblés autour, comme des enfants entourant et consolant leur mère qu'on a outragée », AMC, 7 Géné 4 (C), p. 1-2.

(120) AMC, n.c., 19 février 1866.

(121) AD Isère, L $1477^{\mathrm{D}}$. 
l'absence du régisseur civil Bigillon, deux frères le font clandestinement pénétrer au monastère et le cachent dans la cellule « $K$ », où ils l'approvisionnent par la voûte du grand-cloître en lui délivrant la pitance du chat, qui était soldé par l'État pour préserver les greniers cartusiens des rats. Il y reste plusieurs mois et dessert toujours discrètement les anciennes paroisses des alentours avant de se soustraire une nouvelle fois à une descente de police en se dérobant « dans un placard qui se trouvait au-dessus de la porte de sa chambre à coucher $»^{122}$. De son errance jusqu'à son arrestation dans les bâtiments délaissés de Chalais par le comité de surveillance actif de Voreppe ${ }^{123}$, le 29 brumaire an II (19.11.1793), peu de faits sont dévoilés ${ }^{124}$. Sa captivité n'est guère mieux renseignée. Dom Éphrem rejoint dom Sabastien Palluis, dom Emmanuel Nivière, dom Thadée Forestier, dom Chrysogone Andrau et dom Séraphin Descamps à Saint-Martin-d'En-Haut, où il est enfermé jusqu'en ventôse an II (02.1794-03.1794) ${ }^{125}$. Il quitte Grenoble en compagnie des autres chartreux le 24 (14.03.1794) ${ }^{126}$ et gagne les prisons de Bordeaux le 18 germinal (07.04.1794), après un long voyage jalonné d'étapes : la Côte-Saint-André, Bourgoin, la Verpillière, Lyon, Tarare, Roanne, Saint-Just, Thiers, Clermont-Ferrand, Saint-Avit, Limoges, etc. Selon dom Nivière, ce périple n'a pas émoussé son entêtement ${ }^{127}$. Interné au fort du Hâ puis transféré au Petit Séminaire, dom Coutarel compose de petits sermons en latin sur des billets de papier, le 29 floréal (18.05.1794). Sur l'un d'entre eux, il invoque saint Charles Borromée (1538-1584) ou encore sainte Gertrude de Nivelle (626659), vénérée pour l'aide qu'elle prodigue aux plus démunis, afin d'exalter ses compagnons à la lutte ${ }^{128}$. Il n'est pas le seul chartreux à agir en détention. Exilé sur le vaisseau Le Républicain le 2 frimaire $(22.11 .1794)^{129}$, le groupe profite de l'activité du procureur de Meylan pour supporter la captivité. Il visite les prisonniers, les fortifie et les console par ses « paroles saintes et aimables ». Celui que dom Éphrem compare à un « second Tobie» de Nephtali, leur procure « tous les soulagements corporels qui dépendaient de lui », et les «édifie par les exemples continuels de douceur et de patience [qu'ils voyaient] en lui $»^{130}$. Sa

(122) AMC, n.c., Souvenirs, $\mathrm{f}^{\circ} 8 \mathrm{r}$.

(123) AD Isère, L 233.

(124) AD Isère, 4 E 543.1 D-6-7; AMC, 4 Varia 1, n 45, registre des délibérations du comité de surveillance de Voreppe (29 brumaire an II) ; A.-M. DE Franclieu, op. cit., II, p. 92.

(125) AD Isère, L 226.

(126) AD Isère, L 679.

(127) Tel est le sentiment qu'il donne à ses amis grenoblois dans une lettre écrite de SaintAvit, le 7 germinal. Citée par A.-M. DE Franclieu, op. cit., II, p. 126.

(128) Le billet est encore conservé aux AMC, 3 Cout. 1.

(129) Manseau (abbé), Les Prêtres et religieux déportés sur les côtes et dans les îles de la Charente-inférieure, II, Lille, 1886, p. 428-429.

(130) AMC, 7 Cout 1, p. 38. 
mort le 21 pluviôse an III (09.02.1795), affecte rudement dom Coutarel. Sa condition physique lui permet de survivre jusqu'à sa libération, ordonnée par un arrêté de sureté générale le 11 germinal an III (31.03.1795) ${ }^{131}$.

Relâché à Brouages (Charentes-Maritimes) le 23 messidor (11.07.1795), dom Éphrem regagne le massif de Chartreuse dans l'été et séjourne à Currière et à la Correrie jusqu'à l'an VII. Il y retrouve les réseaux clandestins qui l'avaient aidé à demeurer dans la montagne avant sa captivité, et notamment la famille Charvet, qui le pourvoit en vivres. C'est sans doute cette complicité qui lui permet d'échapper à la surveillance de l'administration centrale de l'Isère qui pour contenir l'offensive des contre-révolutionnaires se renforce en pluviôse an IV (01.1796-02.1796). Malice de l'histoire, le 7 pluviôse (27.01.1796) les autorités interpellent dans la commune de Chartrousse un ancien religieux de la Valbonne, l'ermitage où dom Éphrem avait voulu prononcer ses vœux ${ }^{132}$. Contrairement à trois autres membres de l'Ordre, le chartreux évite l'arrestation des 81 prêtres ordonnée dans tout le département 17 jours plus tard ${ }^{133}$. Si le 2 ventôse (21.02.1796), le commissaire de Saint-Laurent-du-Pont assure l'absence de prêtres insermentés dans son canton ${ }^{134}$, dans une lettre adressée au commissaire de Grenoble le 29 prairial (17.06.1794), le commissaire central du département de l'Isère Jean-François Hilaire constate, non sans raison, qu'un prêtre réfractaire des environs de Grenoble « rend compte à son évêque de tout ce que lui et ses confrères font pour le rétablissement de l'ancien clergé $\rangle^{135}$. Il est difficile de savoir s'il s'agissait de dom Éphrem. En revanche, il est avéré qu'il célèbre des messes et tient les registres baptistaires de Saint-Pierre-de-Chartreuse, entre les 11 et 22 prairial an IV (30.05.1796-10.06.1796) ${ }^{136}$. Un frère déguisé en domestique lui servait la messe dans la sacristie et dissimulait dans la journée les ornements liturgiques dans un recoin des écuries. Il concourt aussi, par la plume, au retour des chartreux. Durant trois ans, il consacre une partie de son temps à l'écriture. À Currière et à la Correrie, il noircit de notes une dizaine de cahiers, où il consigne les usages et cérémoniaux en vigueur à la Grande Chartreuse avant la Révolution. Tous sont remplis de commentaires spirituels et d'oraisons touchant à la vie contemplative et à l'observance régulière de l'Ordre : des varia exercitia ante et post communionem côtoient

(131) Jean Delmas, « Les Prêtres du Cantal déportés pendant la Révolution », RHA, XIII, 1911, p. 13.

(132) AD Isère, L 91, $\mathrm{f}^{\circ} 121 \mathrm{r}$ - $-124 \mathrm{r}$.

(133) AD Isère, L 91,

(134) AD Isère, L 231.

(135) AD Isère, L $114, \mathrm{f}^{\circ} 68 \mathrm{r}$.

(136) AMC, 7 Géné 4 (C), p. 1-2. 
des centaines de prières ou un traité sur le De meditatione seu oratione mentali. Prônant une religion de l'intérieur, le chartreux se réfère notamment à la pensée dévotionnelle et mystique des chartreux rhéno-flamands des XIII et XIV ${ }^{\mathrm{e}}$ siècles. Dom Henri Egher de Kalkar (1328-1408) et dom Johann Gerecht Lansperge (1489-1539) sont les deux auteurs qu'il sollicite le plus souvent pour soutenir son raisonnement. Ses références sont anciennes, à dessein sans doute, pour que les Coutumes de Chartreuse, « ses » Coutumes de Chartreuse, ne soient ni altérées, ni oubliées. Ce travail l'occupe sans doute jusqu'en messidor an XI (27.06.1803), date à laquelle il obtient du Grand-juge et ministre de la Justice un certificat d'amnistie ${ }^{137}$. Comme l'indique la première de couverture d'un de ses livrets, il ne l'achève pas :

« Je me proposai par ce recueil de me procurer un vade mecum en deux volumes dont le premier aurait contenu un règlement de vie, et le second des exercices de piété. Mes occupations ne m'ayant pas permis d'exécuter ce projet, je souhaite que quelqu'un de mes confrères profite des matériaux ici renfermés, pour l'exécution de mon projet, pour la gloire de Dieu et pour sa propre utilité $\rangle^{138}$.

«Fleur du désert », dom Éphrem l'est donc à divers titres. Composer un bouquet à l'image d'un personnage si entier n'est pas chose aisée. Tentons l'aventure. Une tige d'amarante, un soupçon de cigüe, une gerbe d'agératum, une corbeille de houx, des brins de bruyère, des bottes de glaïeul et des brassées d'œillets jaunes conviendront à coup sûr. D'abord l'amarante, ornement de l'amour durable, pour l'inclination précoce que le moine porte à la vie cartusienne et pour l'affection indéfectible qu'il affiche durant toute la Révolution à l'égard de sa famille religieuse. De la cigüe, des agératums et du houx, figurations de la confiance, pour un moine qui durant près de vingt ans concourt à maintenir illégalement la présence et l'esprit des chartreux dans les montagnes qui les avaient accueillis 700 ans plus tôt. La bruyère et le glaïeul encore, fleurs des rêveurs solitaires et des personnes aimant relever des défis, pour ce chartreux qui, entre 1795 et 1798, jette peut-être sans le savoir les fondations $\mathrm{du}$ 《 propos » cartusien du $\mathrm{XIX}^{\mathrm{e}}$ siècle en fossilisant par écrit la tradition de Chartreuse de 1789. Des œillets jaunes enfin, attributs des êtres exigeants, pour ce père vicaire de Chartreuse qui, en 1824, guide sur le sentier de la vie cartusienne le futur général dom Jean-Baptiste Mortaize (1831-1863), dont il confirme l'élection en 1831, à condition qu'il « ne change rien aux Statuts, ni 
aux anciens usages et coutumes de l'Ordre ». Son zèle et sa vigilance pour la conservation du rite durant la période de transition que la Chartreuse connait entre 1816-1830, où chaque membre d'une communauté recomposée de vieillards ayant 40, 50 ou 60 ans de profession souhaite imposer les usages de $s a$ maison quand la nouvelle génération espère quelques mitigations, vont s'avérer déterminants. Les racines de cet engagement puisent au plus profond dans le terreau des affrontements idéologiques soutenus durant la Révolution. Le «Statut, tout le Statut, rien que le Statut ${ }^{139}$. Ne quid nimis.

Laurent BORNE

Doctorant, Centre d'histoire « Espaces et cultures » Université Blaise-Pascal (Clermont II) 4 , rue Ledru 63057 Clermont-Ferrand Cedex 1 lborne@yahoo.fr 